\title{
Die Literatur der letzten zehn Jahre über die bösartigen Tumoren des Auges.
}

\author{
(Sammelreferat.) \\ Ton \\ Dr. M. Mannheimer, \\ tugenarzt in Berlin.
}

Zur allgemeinen Orientierung sei vorausgeschickt, daß unter dem Begriff des Auges nicht der Bulbus allein, sondern der Augapfel und alle seine Adnexe verstanden werden sollen. Denn wenn auch die Geschwülste der Lider, des Tränenapparates, der Orbita, der Conjunctiva ihrer Genese und ihrer Histologie nach kaum wesentliche Unterschiede von denen anderer Organe ron entsprechendem Bau aufzuweisen haben, so sollen sie doch hier ihre Erwähnung finden. Durch die engen anatomischen und physiologischen Beziehungen der Hilfsapparate zum Augapfel, sowie durch die Art der Ausbreitung der von diesen ausgehenden Tumoren und durch das besondere Verhalten des Bulbus scheint eine Berechtigung hierzu gegeben zu sein.
1. Tumoren der Lider (ausschlieBlich der von den Meibom. schen Drüsen ausgehenden).

Die Mehrzahl der Arbeiten befaßt sich, der Häufigkeit derselben entsprechend, mit den epithelialen Neubildungen, für welche sich die verschiederssten Namen vorfinden: Carcinom, Cancroid, Epitheliom, Papillom. Palich-S zanto bespricht die verschiedenen Formen des Lidkrebses, indem er die bis zum Jahre 1915 bekannten Fälle zusammenstellt ${ }^{383}$. Dazu bringt er 10 neue eigene Beobachtungen, die bis auf einen Fall Basalzellenkrebse waren. Ein Adenocarcinom, von den Schweißdrüsen ausgehend, erwähnt Coats ${ }^{118}$ ). Ausdrücklich betont wird, daß nicht die Mollschen Drüsen der Ursprungzort waren, da in den Schnitten sich keine Cilienfollikel fanden. De La pers on ne bringt ein ausgedehntes Carcinom, das zur Atrophie des Lides und der Orbita geführt hatte ${ }^{307}$ ). - Einen breiten Raum nimmt die Therapie der Lidcarcinome ein. Der Standpunkt des operativen Fingriffes wird vertreten von Fischer ${ }^{179}$ ), der nur bei kleinen Krebsen die Kauterisation gelten lassen will, von (hevalie ${ }^{110}$ ), Ziegler ${ }^{578}$ ). $\mathrm{Bach}^{41}$ ). Krauss ${ }^{300}$ ), Hage nbacherite, Elschnigi65). In den letztgenannten Arbeiten handelte es sich um ausgedehnte Fälle, in denen Lidplastiken nötig waren. Therapeutische Bestrahlung, und zwar entweder mit Radium oder mit Röntgenstrahlen oder auch kombinierte wird empfohlen von Hirsch ${ }^{245}$ ), Tischner ${ }^{510}$ ), Poulard ${ }^{414}$ ), Burtzef ${ }^{90}$ ), Boussi ${ }^{84}$ ), Axenfeld ${ }^{38}$ ), José Garcia del Mazo ${ }^{318}$ ), Rauch ${ }^{422}$ ), Stargard $\left.t^{483}\right)$, Burk ${ }^{88}$ ), Schimanows $\mathrm{ki}^{456}$ ), der die Wirkungsweise des Radiums in einer Cmstimmung der Energie der Epithelzellen sieht, aus denen sich Krebszellen bildeten, Cavara $\left.{ }^{104}\right)$, E. von Hippe ${ }^{244}$ ), Pe ppmülle ${ }^{389}$ ). Alle 
Autoren betonen die Unschädlichkeit der Bestrahlungen für das Auge selbst, den guten Eifolg bei frühzeitiger Behandlung, weisen jedoch z. T. darauf hin, daß nur zuverlässige Patienten für die konservative Therapie geeignet sind. Einen ablehnenden Standpunkt nebmen Rollet und Genet ein ${ }^{41}$ ). Über eine Art Selbstheilung eines adenoiden Hautearcinoms, wenn auch nicht von Dauer, wird von Lindenmeyer berichtet ${ }^{324}$ ); sie trat im Verlauf eines Gesichtserysipels ein dadurch, daß der Tumor einschmolz und sich überhäutete. Nach $1 / 2 \mathrm{Jahr}$ trat jedoch ein Rezidiv auf. - Über eine andere Art konservativer Therapie finden sich Angaben hauptsächlich in der italienischen Literatur. Gute Erfolge mit dem

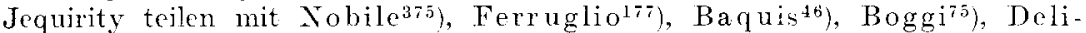
tala $\left.{ }^{138}\right)$, der in wenigen Tagen Heilung sah, welche er mikroskopisch bestätigen konnte. Ebenfalls günstige Wirkung stellt fest Bialet $\left.\mathrm{i}^{64}\right)$, nacli dessen Meinung das Jequirity eine direkte biotoxische Wirkung auf die Geschwulstzellen ausübt, insofern als diese wegen Entwicklnng ron Auflüsungsprozessen die Fähigkeit verlieren, die nährenden Substanzen, welche die Vergrößerung der Geschwulst be wirken, anzuzichen. Kriw on os of und Perim off berichten über ein Carcinom, das nach ihrer Nethode operiert wurde $\left.{ }^{302}\right)$. - Ingewölmlichere Formen von Lidkrebs erwähnen $A t^{17}$ ) und Ma urizi ${ }^{344}$ ); im ersten Falle handelte es sich um ein cystisches Adenocarcinom, das von einer Talgdrüse ausging. Eine genaue klinische und histologische Darstellung eines Naevuscarcinoms gibt Marongi $u^{339}$ ). Besonderes Interesse verdienen noch die Arbeiten von Giri209), der ein primäres Oberlidcarcinom beschreibt, das durch Kontaktinfektion zweimal zu einem sekundären Cnterlidkrebs und einmal zu cinem Hornhautcarcinom führte, sowie von Lindner ${ }^{326}$, der entgegen früheren Anschaumgen das gleichzeitige Vorkommen von Careinom und Tuberkulose erwähnt. Er zeigt das Präparat eines Lid-Epithelioms, wo sich im subcutanen Gewebe tuberkulöse Veränderungen mit typischem Knötchenaufbau (Epitheloidzellen, Riesenzellen und Nekrose) fanden. 'Tuberkelbacillen waren allerdings nicht nachweishar. Ein Epitheliom, das sich aus einem bestehenden Dermoid entwickelte, beschreibt I) uclosit8). Pokrow. $\left.s k y^{402}\right)$, Fischer $\left.{ }^{179}\right)$, Weekers ${ }^{538}$ ), Dodd ${ }^{147}$ ) bringen Kasuistik.

Eine Einteilung der Lidsarkome gibt Pereyra ${ }^{391}$. Fr unterscheidet von der Conjunctiva, rom Tarsus und von den verschiedenen (ieweben rom Tarsus bis zur Haut ausgehende Sarkome. Als Beleg bringt er einen eigenen Fall von Angiomelanosarkom, ron der Conjunctiva palpebralis ausgehend, in dem er den Crsprung der verschiedenen Geschwulstelemente nachweist. Einen statistischen Überblick über die Häufigkeit der Sarkome, über Art, Sitz, Verteilung auf die Lebensalter, Crsachen usw. gibt Schiller $\left.{ }^{45}\right)$. In den meisten Arbeiten wird die große. Malignität des Sarkoms betont, das rasch in die Tiefe wuchert und Drisenmetastasen macht. Dabei leistet der Bulbus selbst so starken Widerstand, daB er von Tumormassen völlig umwuchert werden kann, ohne selbst von diesen ergriffen zu sein ${ }^{528}$ ). Was die einzelnen Formen des Sarkoms betriff, so werden, wie auch sonst, unterschieden: Adenosarkome ${ }^{434}$ ), Angiosarkome ${ }^{400}$ ), Lymphangio-Endotheliome ${ }^{581}$ ), Rundzellensarkome ${ }^{504}$ ), Spindelzellensarkome ${ }^{266}$ ), Riesenzellensarkome ${ }^{408}$ ), Mvxosarkon ${ }^{469}$ ), papilläre Sarkome ${ }^{180}$ ), Melanosarkome $\left.^{549},{ }^{199}\right)$, Leukosarkome $\left.{ }^{62}\right)$. Von einem elephantiastischen Sarkom bei einem $1^{1 / 2}$ jährigen Kinde berichtet Terrie $\left.n^{505}\right)$; Literatur findet sich bei Bertscher ${ }^{62}$ ) und bei 'Teitz ${ }^{504}$. Anläßlich der Beschreibung cines Fibrochondroendothelioms weist Wick auf die Schwierigkeit der klinischen und histologischen Unterscheidung zwischen Epitheliom und Endotheliom hin $\left.{ }^{558}\right)$. Mit Sicherheit will er sie nur voneinander trennen, wenn es gelingt, den Ausgangspunkt der Neubildung zu finden. - Über das sehr seltene Peritheliom handeln die Arbeiten von R. Scott La m b ${ }^{305}$ ) und ron Eicke $\left.{ }^{160}\right)$. 


\section{Tumoren der Meibomschen Drüsen.}

van Duyse (fils) weist darauf hin, daß die Carcinome hier eigentlich Mischgeschwülste sind, insofern als in ihnen,,epithèles pavimenteux und epithèles glandulaires" vorherrschen ${ }^{156}$ ). Dies wird (wie bei den speicheldrisen) entwick. lungsgeschichtlich so erklärt, daB das Ektoderm Haut-und Drüsenepithel bildet. Bei atypischer Entwicklung entsteht ein Tumor (autochthon und autonom im sinne Ribberts). van Du yse hält diese Geschwülste für relativ gutartig. Da-

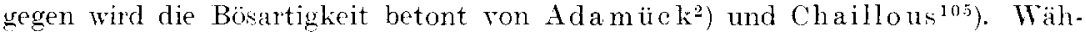
rend die Adenome im allgemeinen gutartig sind, teilt Hesse cinen Fall mit, den er sowohl klinisch als auch anatomisch als Cbergang zum malignen auffa $B t^{242}$ ). - Sonstige Beiträge liefern Smirnow ${ }^{480}$ ), Tolstouchow ${ }^{512}$ ), Pokrows $\mathrm{ky}^{401}$ ), Scheerer ${ }^{453}$ ).

\section{Tumoren der Tränendrüse.}

Eine genane histologische Darstellung der sog. Mischgeschwülste der Tumoren gibt Birch-Hirschfeld, indem er 75 Fälle der Literatur bespricht, denen er einen eigenen hinzufügt ${ }^{66}$ ). In ihrem Bau und in ihrer Genese ähneln sie den Geschwülsten der Speicheldrüsen. Dieselben Tumoren behandeln de Lapersonne ${ }^{308}$ ), Hende $\left.z^{356}\right)$, Knap $p^{289}$ ), van Duyse $\left.{ }^{154}\right)$, Katz ${ }^{280}$ ). Pascheff bringt die histologischen Befunde von lymphatischen, epithelialen und Bindegewebstumoren ${ }^{386}$ ), Elliot und Ingram, die Anatomie von 6 rerschiedenen Tumoren ${ }^{163}$ ), Or mond ein Rundzellensarkom ${ }^{381}$ ), We lls und Ma you ein Lymphosarkom ${ }^{547}$ ), Boettger ein Chondrosarkom ${ }^{73}$ ). Cnter Zusammenstellung der Literatur seit 1909 bespricht Habermann ein Spindelzellensarkom ${ }^{2 * 5}$ ). Als Besonderheit sei ein metastatisches $L_{y}$ m phosarkom erwähnt $\left.{ }^{159}\right)$ : rechts fand sich in der Tränendrüse, links in der Orbita eine Metastase. Über das Endotheliom der Tumoren liegen zwei Arbeiten vor ${ }^{72},{ }^{572}$ ). Ein malignes Adenom erwähnt Brose $\mathrm{e}^{87}$ ), ein Adenocarcinom Wigods $\mathrm{ky}^{560}$ ), epidermoidale Carcinome von besonderer Malignität $\mathrm{JaCk}^{258}$ ) und $\mathrm{Howard}^{256}$ ).

\section{Tumoren des Tränensackes.}

Sie sind verhältnismäßig selten; der von Snegirew veröffentlichte Fall eines Rundzellensarkoms ist der scchste in der Literatur ${ }^{481}$ ). Butler reiht einen weiteren Fall an, der im Beginn für Tuberkulose gehalten wurde $\left.{ }^{91}\right)$. Ein Lymph. angio-Endotheliom wird von Perrod beschrieben ${ }^{392}$ ). ein Epitheliom von Pasetti ${ }^{388}$. Schlindwein demonstriert eine maligne Erkrankung des Tränenröhrchens ${ }^{458}$ ); die Art derselben konnte aus Mangel des Originals der Arbeit nicht eruiert werden.

\section{Tumoren der Plica semilunaris.}

Ein Melanos arkom wird von Rolandi beschrieben ${ }^{437}$ ). Histologisch fanden sich polygonale, z. 'T. pigmentierte Zellen epitheloiden Charakters, außerdem drüsige Bildungen, welche aus der oberflächlichen Epithelauskleidung (Schleimhautkrypten) ihren Lrsprung nahmen.

\section{Tumoren der Caruncula lacrymalis.}

Eine Klassifikation gibt Beauvieux ${ }^{48}$ ), indem er nach dem Crsprungsgewebe epitheliale, bindegewebige und aus beiden Geweben bestehende Tumoren unterscheidet. Wätzold kommt, da die Karunkel entwicklungsgeschichtlich aus einer Hautfalte hervorgeht, zu dem Schluß, daß Erkrankungen und Geschwülste denen der Haut gleichen ${ }^{536}$ ). Im ganzen sind sie überhaupt ziemlich selten (unter 60000 klinischen Patienten nur 6 Fälle von Karunkeltumoren). Einen malignen Naevus von epithelialem Bau beschreibt Stoewer, wobei er unentschieden läßt, 
ob die Naevuszellen vom Epithel oder vom Bindegewebe abstammen ${ }^{495}$ ). Danis ${ }^{134}$ ), Menacho ${ }^{3 \overline{4}}$ ) und Deruche ${ }^{142}$ ) erörtern das Carcinom; in dem letrten Fall handelte es sich um doppelseitigen Krebs, In dem Fall von Cords hatte sich nach einem Trauma ein Carcinom entwickelt und war auf die Orbita übergegangen $\left.{ }^{128}\right)$. Die Papillome kommen nach Boudier et Velter sehr selten vor $^{82}$ ); erst 5 sollen bis 1912 beschrjeben sein. Histologische Befunde von Pa. pillomen geben (Coats $\left.{ }^{120}\right)$ und Fromaget $\left.{ }^{188}\right)$. Endlich sei erwähnt ein Lymphosarkom²62), das lymphdrüsenähnlichen Bau hatte; wahrscheinlich hatte es sich aus dem adenoiden Gewebe der Submucosa der Karunkel entwickelt.

\section{Tumoren der Conjunctiva.}

Relativ gutartige Tumoren sind dic Pa pillome; sie neigen jedoch zur carcinomatösen (mwandlung, worauf Frevtag hinweist ${ }^{186}$ ). Rutschmann betont, daß das anatomische Bild ein gutartiges sein kann, während der klinische Verlauf maligne ist wegen mehrfacher Rezidivierung ${ }^{450}$ ). Pasetti meint, daß Geschwülste, die anfangs für Papillome gehalten wurden, aber rezidivierten oder sonst bösartigen (harakter annahmen, immer (arcinome waren ${ }^{387}$ ). Wie anderswo, so treten auch auf der Bindehant die Papillome multipel auf ${ }^{332}$ ). Von großer Flächenausdehnung der Geschwïlste berichten Wirtz ${ }^{567}$ ) und Herbert582). Gutartig scheinen die Fälle von $B\left(a c k^{70}\right.$ ) und von $K r a u s s^{299}$ ) gewesen zu sein. Ein durch Probeexcision nachgewiesenes tuberkulöses Geschwür, das nach Entfernung eines Papilloms auftrat, beschreibt Pete $\mathrm{r}^{395}$ ). -- Die große Rolle, welehe hei uns die Naevi für die Entstehung von malignen 'Tumoren spielen, kommt ihnen nach Steiner bei Javanem. (hinesen, Indern, Arabern usw. nicht zu, bei denen sich vielfach pigmentierte Bindehaut findet ${ }^{487}$ ). So gut wie nie entwickeln sich aus den Pigmentnaevi maligne Geschwülste. - Carcinom und Sarkom lassen sich oft klinisch nicht unterscheiden ${ }^{238}$ ). Aber auch histologisch gibt es Tumoren, in denen Anhaltspunkte für beide Arten vorhanden sind 251,60 . Von Sarkomen, die sich aus Naevi entwickelt hatten, handeln die Arbeiten von Ro per ${ }^{444}$, Bergmeister ${ }^{5}$ ), (xallemaerts $\left.{ }^{200}\right)$, Korschenjanz $\left.{ }^{296}\right)$, Pokrows $\left.y^{399}\right)$, Heller ${ }^{238}$ ), Pons Marqués $\left.{ }^{406}\right)$, Trapezontzeff ${ }^{515}$, Romer ${ }^{43}$; ; in den meisten Fällen lagen Spindelzellensarkome ror, die pigmentiert waren. Der Fall ron Höfle war unpigmentiert=51). Nach einer Atzung der Bindehaut mit Kalk entstand ein Melanosarkom ${ }^{390}$ ). Das Lymphosarkom behandeln ( asolino ${ }^{100}$ ) und Coats ${ }^{117}$ ), und Wenzel bringt einen malignen Tumor alveolärer Struktur.58). Eine Arbeit findet sich über Röntgenbestrahlung des Sarkoms: nach Braunschweig verschwand die Geschwulst ${ }^{85}$ ). Infolge von Drüsenmetastasen eintretender Exitus letalis ließ es nicht zum Rezidiv kommen. - Von den e pithelialen Geschwülsten sei erwähnt das Dermoepitheliom (Parinaud), von dem Colombo eine histologische Beschreibung gibt $\left.{ }^{123}\right)$. Ein Epitheliom, das die ganze Hornhaut überzogen hatte, bringt Vease $\left.y^{54}\right)$. Das seltene Epithelioma papillare behandeln Cosmettatos $\left.{ }^{29}\right)$, der den Schluß auf Malignität aus dem Durchtreten der Epithelzellen durch die Basalmembran und ihrem Eindringen in die Papillen zieht, sowie Addario ${ }^{3}$. Als cin Locus minoris resistentiae muß ein Pterygium angesehen werden, auf dessen Boden Wiener und Alt ein Epithelioma papillare beobachtet haben ${ }^{559}$ ). Eine besondere Ceschwulst, die er ("ylindroepitheliom nennt wegen der Gruppierung der großen, unregelmäßig polygonalen, plasmareichen Zellen um die Gefäße herum, beschreibt NI. Miille ${ }^{365}$ ). Über die Art der Entstehung des (arcinoms spricht Wolfr $\mathrm{m}^{568}$ ), ïber multiple (ancroide Montin ho $0^{362}$, wähend Burney einen Fall ron diffuser careinose der palpe. bralen und epibulbären (onjunctiva mitteilt ${ }^{85}$ ). Auch hier handelte es sich wie in den anderen Fällen um einen Plattenepithelkrebs. Ein Kontaktearcinom 
beschreibt $E y m a n n^{168}$ ): gegenüber einem primären Basalzellenkrebs (Krom. pecher) der Bindehaut fand sich eine carcinomatöse Wucherung des Hornhautepithels und der angrenzenden Bindehaut. Endlich sei eine ungewöhnliche epitheliale Geschwulst erwähnt, die Alt für einen unpigmentierten Naevus cysticus hält $\left.{ }^{22}\right)$ : in die Tiefe dringende Epithelzapfen zeigen Einschmelzung der zentralen Zellen, wodurch es zu einer Lücken-(Cysten-)Bildung kommt.

\section{Tumoren des Limbus corneae.}

Nach lind sind die wichtigsten Tumoren Papillome, Sarkome, Carcinome, Epitheliome $\left.{ }^{320}\right)$. Da sich bei manchen Menschen Pigment am Limbus findet, so kommen auch melanotische Geschwülste vor. Häufig entwickeln sich die Tumoren aus vorhandenen Naevi [Sarkom bei von Hoor ${ }^{25}$ ), (ajcinom bei Offret ${ }^{378}$ )]; von einem naevusähnlichen Bau sprechen Clunet et Offret, die gleichzeitig darauf hinweisen. daß die Tumoren häufig bei Menschen mit braunem Teint rorkommen $\left.{ }^{16}\right)$. Eine allgemeine Betrachtung über die Tumoren des Limbus gibt Pignatori ${ }^{583}$ ). - - Bei den Papillomen unterscheidet Contino zwei Formen: kleine mit enormer Proliferation des Epithels, aber geringer Bindegewebsentwicklung und solche mit reichlicher Bindegewebsproliferation $\left.{ }^{126}\right)$. Clcerationen und Nekrosen wie beim Epitheliom sollen beim Papillom fehlen. Eins ron der (rsten Art wird von Heilbrun beschrieben $\left.{ }^{236}\right)$. Die Wichtigkeit der histologischen Lntersuchung betont Rosenhauch, um nicht Carcinom-Degeneration zu übersehen $\left.{ }^{46}\right)$. Valli berichtet über cinen mehrfach rezidivierten Fall, bei dem die Hornhaut beteiligt war unter Lsurierung der Bowmanschen Nembran ${ }^{521}$ ). Von einem Carcinom, das ebenfalls in den Lymphspalten der Cornea weiter gewuchert war, konnte $W$ intersteiner die Präparate zeigen ${ }^{565}$ ). In dem Fall von Schweinitz entwickelte sich ein Papillom nach einem Stich mit einer Fischgräte ${ }^{466}$. Da die Conjunctiva der Limbusgegend dieselbe Struktur hat wie die Haut, so finden sich nach Borch hier auch zwei Arten von epithelialen Tumoren: Epitheliome und Plattenepithelcarcinome $\left.{ }^{79}\right)$. Diese sind seltener, aber bösartiger. Beide können rezidivieren, ins Bulbusinnere dringen, Vetastasen machen. Sie schrejten fort entweder durch die Fontanaschen Räume in die Vorderkammer oder zwischen Sclera und Ciliarmuskel durch die Aderhaut. In dem Fuchsschen Fall blieb diese allerdings frei, obgleich das Limbuscarcinom entlang den vorderen Ciliargefäßen ins Bulbusinnere drang ${ }^{193}$ ). Aus den tieferen Schichten der Hautbestandteile eines Dermoids entwickelte sich bei Duclos ein PflasterzellenEpitheliom ${ }^{148}$ ). Sonst erwähnen noch (arrinome Maggi ${ }^{334}$ ), der eine Ċbersicht $^{2}$ gibt, und Heilbrun³6). Eine atypische Epithelwucherung, bei der er nicht entscheiden will, ob es sich um ein beginnendes Carcinom oder um Wucherung auf entzündlicher Basis handelt, beschreibt Höhne ${ }^{252}$. - Über das Sarkom bzw. Melanosarkom sprechen Jessop ${ }^{265}$ ), Crigle ${ }^{131}$ ), der darauf hinweist, daß die Sclera und Cornea erst spät befallen werden, weil jene sehr widerstandsfähig und diese gefäßarm ist, ferner Filatow ${ }^{178}$ ) und Schwe $\mathrm{k}^{472}$ ). Auch im Falle Böhms, wo es sich um ein in die Fläche wachsendes adenoides Carcinom handelte, blieben Cornea und Sclera frei $\left.{ }^{76}\right)$. Endlich seien die Arbeiten erwähnt, welche sich mit der Therapie beschäftigen. $\ddot{C} b e r$ eine Jequirityheilung eines Rezidivs eines Epjthelioms berichtet $\mathrm{Zani}{ }^{5 / 3}$ ), über eine solche durch Radiumbromid Collins ${ }^{122}$ ), der die guten Aussichten dieser Therapie wegen der Widerstandsfähigkeit der Sclera betont. In einer Arbeit über Radiumtherapie bei Augenleiden erwäbnen New und Benedict 97 Lidepitheliome, sowie 2 des Limbus und 12 der Orbita, die in gleicher Weise behandelt wurden ${ }^{374}$ ). Wessely hatte Erfolg mit Mesothorium ${ }^{556}$ ), Albers-Sch önberg mit Röntgenstrahlen ${ }^{9}$ ), während Danis die energische Anwendung des Thermokauters empfiehlt ${ }^{135}$ ). Dagegen 
mußte D u n bar Roy nach vergeblicher Bestrahlung zur Exenteration schreiten ${ }^{150}$ ). Durch eine durch hochfrequenten Strom erzeugte Flamme will Chance eine trockene Nekrose bei Sarkomrezidiven erzeugen ${ }^{107}$ ).

\section{Tumoren der Hornhaut.}

Eine große Zahl von Arbeiten beschäftigt sich mit dem Papillom. Dabei kommen Reis ${ }^{426}$ ), Wicherkiewicz ${ }^{557}$ ), Piccaluga ${ }^{396}$ ) zu der Überzeugung, daß es sich fast immer um primär vom Limbus ausgehende Neubildungen handelt. Nach Reis ${ }^{426}$ ) entsteht das echte Hornhautpapillom immer auf dem Boden einer chronischen, entzündlichen Veränderung (beschreibt einen Fall, bei dem sowohl in situ mit dem Hornhautmikroskop, als auch nach der Excision histologisch die Diagnose bestätigt werden konnte. Die papilläre Neubildung sa $\$$ meist oberhalb der Bowmanschen Membran; an einzelnen Stellen hatte jedoch das Epithel Neigung ins Stroma zu wuchern, ohne daß es von Bindegewebe begleitet wurde [carcinomatöse Degeneration!]). Von carcinomatöser Degeneration spricht auch Poleff ${ }^{404}$ ): „Anaplasie der Zellen, Polymorphie des Kernes." Auf die Entstehung auf dem Boden einer Entzündung weist der Fall von Blagoweschtschensky hin, wo ein Pannus trachomatosus bestand ${ }^{71}$ ). Kasuistik bringt die Arbeit von Schäfle $\left.{ }^{452}\right)$. Die Differentialdiagnose zwischen Papillom und Epitheliom ist nicht leicht zu stellen: Li b b y läßt die Frage in seinem Fall sogar unentschieden ${ }^{319}$ ). Und Piccal uga kommt in seinem Fall zu dem Schluß, daß es sich um eine Mischgeschwulst von Papillom und Epitheliom handelt ${ }^{396}$ ). Auch Steinohrt spricht von einem Nebeneinander von papillärer und epithelialer Struktur. Als Erklärung faßt er zwei Möglichkeiten ins Auge: entweder ist ein ursprünglich papillomatöser Tumor krebsig entartet, oder es hat sich in einem primären Epitheliom sekundär papillomatöses Gewebe entwickelt ${ }^{488}$ ). An Hand eines histologisch beschriebenen Falles von Epitheliom stellt Alessandro histogenetische Betrachtungen an über die echten Neubildungen überhaupt ${ }^{10}$ ). - Die Widerstandsfähigkeit der Hornhaut gegenüber der Invasion eines epithelialen Tumors betont Bossalino ${ }^{80}$ ), und zwar leistet nach ihm im wesentlichen die Bowmansche Membran die starke Resistenz. Erst wenn diese durch Zerfall von Fasern vermindert ist, kann die Geschwulst in die Tiefe wuchern. Zu einer eigentlichen Perforation kommt es nicht. Profeta ${ }^{415}$ ), Cunningha m${ }^{132}$ ), Menacho ${ }^{354}$ ), Manoles $\mathrm{co}^{338}$ ), Hirs $\mathrm{ch}^{247}$ ) liefern kasuistische Beiträge; ersterer betont ausdrücklich, daß in seinem Fall Limbus und Conjunctiva sclerae frei waren. - Das Sarko m der Hornhaut scheint nicht sehr häufig zu sein; Knape führt in seiner Arbeit bis zum Jahre 1910 10 Fälle der Literatur an; in seinem Fall handelte es sich um ein von einem Gerontoxon ausgehendes polymorphkerniges Sarkom mit reiohlichen Riesenzellen und pigmentierten Zellgruppen ${ }^{288}$ ). Ein Rundzellensarkom, das gleichfalls pigmentiert war, beschreibt Addario-Ferta ${ }^{4}$ ), ein Sarkom aus großen ovalen, bzw. spindelförmigen, z. T. pigmentierten Zellen De a $\mathrm{n}^{137}$ ), einen rasch rezidivierenden sarkomatösen Tumor Palmieri ${ }^{385}$ ). - Die Therapie, und zwar die mit Radium und Mesothorium bzw. Röntgenstrahlen wird behandelt von Agricola ${ }^{6}$ ), der bei einem fünfmal rezidivierten Papillom durch Mesothorium Heilung erzielte (10 Monate beobachtet), sowie von Guglianetti $\left.{ }^{223}\right)$, Mattice $\left.{ }^{343}\right)$, Burk $\mathbf{k}^{88}$ ).

\section{Epibulbäre Tumoren.}

Hier soll über die Arbeiten berichtet werden, aus denen, sei es wegen Unzulänglichkeit des Originals, sei es, weil die Autoren sich nicht darüber ausgesprochen haben, der Ursprung der Geschwülste nicht eruiert werden konnte. Daß bösartige Tumoren epibulbär bleiben, liegt an der großen Widerstandsfähigkeit der Sclera: in den beiden Fällen Ca s olinos entwickelten die Epitheliome sich zu bedeutender 
Grö $\left(\mathrm{e}^{99}\right)$, und Verhöff beschreibt ein Sarkom, bei dem der Augapfel völlig von Tumormassen umgeben, aber vollständig unbeteiligt war ${ }^{528}$ ). Die epithelialen Tumoren werden als relativ gutartig bezeichnet ${ }^{\mathbf{1 3 0}},{ }^{\mathbf{8 3}}$ ). Ǘber das Zusammentreffen von Xeroderma pigmentosum und Epitheliom bzw. Carcinom berichten Migliorino ${ }^{358}$ ) und $\mathrm{Max}^{345}$ ); in dem letzten Falle war es zu einer Atrophie der Iris gekommen. - Von den Sarkomen finden sich die verschiedenartigsten erwähnt;

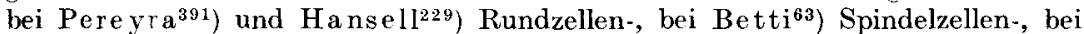
Dickson ${ }^{145}$ ) ein Leukosarkom. Nach einem perforierenden Trauma entwickelte sich ein Sarkom in dem Falle von Vease e ${ }^{523}$ ). Bemerkenswert ist die Beobachtung von $\mathrm{Stă} 1$ berg ${ }^{482}$ ): bei einem extrabulbären Sarkon, das allerdings bereits teilweise die Sclera ergriffen hatte, bestanden ausgedehnte iridochorioiditische Veränderungen sowohl des befallenen Augapfels als auch des anderen. Die Frage, ob diese Uveitis als s y m path is che anzusehen ist, läßt Verfasser offen. In einem Fall von Koller fanden sich Kontaktmetastasen des Cnterlides ${ }^{293}$ ). Einen Fall von epibulbärem Sarkom aus Japan berichtet Komoto ${ }^{294}$ ); dasselbe ist dort äußerst selten. - Grandclément $\mathbf{t}^{214}$ ) sah mit Röntgenstrahlen und Radium guten Erfolg bei einem Epitheliom, Braunschweig ${ }^{85}$ ) bei einem Sarkom. Auch bei anderen malignen Tumoren vom Charakter der Pigmentnaevi wird von Chevallereau, Offret et Boussi konservative Therapie empfohlen $\left.{ }^{112}\right)$.

\section{Tumoren der Sclera.}

Hierher gehörig sind nur die Arbeiten von Greeves ${ }^{218}$ ) und von Nelson ${ }^{371}$ ), der ein Sarkom entfernte, das ohne Rezidiv blieb.

\section{Tumoren der Augenmuskeln.}

Als primäre Geschwülste finden sich drei Sarkome angegeben ${ }^{342},{ }^{274}$ ), und zwar saBen alle im Musculus rectus superior. In dem Falle von Maruo war ein Trauma vorausgegangen. Über ein metastatisches endotheliales Sarkom im M. rectus inferior berichtet $\mathrm{Biet} \mathrm{ti}^{65}$ ); der primäre Tumor war retroperitoneal gelegen. Im Falle Heurtels war ein Zylinderzellencarcinom, wahrscheinlich von der Tränendrüse ausgehend, auf die äußeren Augenmuskeln übergegangen, diese teils umhüllend, teils Krebsherde in der Muskelsubstanz bildend ${ }^{243}$ ).

\section{Tumoren der Nerven des Auges (a usschließlich Sehnerv).}

Chaillous spricht in einer Arbeit über die Metastasen der bösartigen Geschwülste an der Basis der motorischen Nerven des Auges davon, daß diese frühzeitig befallen sein können ${ }^{106}$ ).

\section{Tumoren der Iris.}

Die weitaus größte Zahl der vorliegenden Arbeiten behandelt die am häufigsten vorkommenden Geschwülste, die Sar kome. Meist handelt es sich um pigmentierte Tumoren; nur vereinzelt ist ausdrücklich die Rede von Le u kos ar ko me ${ }^{204},{ }^{28}, 508$ ); letzteres zeigte relative Gutartigkeit. Dieselbe bestand auch in dem Falle von Wra $y^{571}$ ), der die Frage unentschieden läßt, ob es sich um eine sarkomatöse Degeneration eines Naevus handelt. Ask bejaht sie in seinem Fall ${ }^{33}$ ). Gleichfalls aus einem Naevus entstanden war das Spindelzellensarkom von Pindikows ki ${ }^{397}$ ), der sich über die weitere Ausbreitung des Tumors ausläßt, die hier wie im Falle Lavens ringförmig war $\left.{ }^{310}\right)$. Kaleschnikof ${ }^{279}$ ) und Delmonte ${ }^{140}$ ) sprechen vom Befallensein von Iris und Ciliarkörper; der primäre Sitz der Geschwulst war nicht mehr zu erkennen. Kasuistische Beiträge liefern $\mathrm{Harms}^{230}$ ) (2 Fälle), Ste phens o ${ }^{490}$ ), Lat tor $f^{309}$ ), der von einem 30 jährigen Bestehen der Geschwulst 
berichtet, Elschnig $\left.{ }^{164}\right)$, Faye ${ }^{173}$ ), Huston Bell ${ }^{50}$ ). Els chnig bringt außerdem 2 Fälle von Endotheliom. In dem von Raubitschek mitgeteilten Falle fand sich eine Partie von unpigmentiertem Gewebe vom Charakter des Spindelzellensarkoms, das an ein Endotheliom erinnerte, und eine zweite Partie aus vielgestaltigen, pigmentreichen Elementen ${ }^{421}$ ). Nimmt man an, daß die Pigmentteile ihren Ursprung aus den Chromatophoren herleiten, so läge eine Mischgeschwulst von Endotheliom und Melanosarkom vor (zum erstenmal beschrieben). Entstehen jedoch nach Ribbert beide Partien aus den Chromatophoren, so handelt es sich um ein Melanosarkom in verschiedenen Entwicklungsstadien. Ein Spindelzellensarkom mit proliferierender Chorioiditis und mikroskopischer Höhlenbildung in der Fovea centralis beschreibt Alt ${ }^{18}$, wobei er zu dem Schluß kommt, daß das strukturlose Bindegewebe in der Aderhaut keine Metastase darstellte, sondern vielleicht schon kongenital vorhanden war. Über ein metastatisches Sarkom spricht Stephens on ${ }^{491}$ ). Gifford suchte ein Leukosarkom durch Radium therapeutisch zu beeinflussen; der Tumor zeigte eine Verkleinerung ${ }^{204}$ ). Zum Schluß zwei äußerst seltene Geschwülste: ein malignes Leio$\mathrm{m} \mathrm{yom}^{153}$ ) und ein metastatisches Carcinom ${ }^{513}$ ), das nach einem operierten Mammacarcinom, bei dem die retroclaviculären Drüsen nicht entfernt worden waren, doppelseitig aufgetreten war.

\section{Tumoren des Ciliarkörpers.}

Bei der engen anatomischen und physiologischen Verwandtschaft von Ciliarkörper und Iris bringen die Arbeiten über die Tumoren des Ciliarkörpers ähnliches wie die über die Geschwülste der Iris. Eine Literaturübersicht findet sich bei Stengele ${ }^{489}$ ). Außerdem wird ein Spindelzellensarkom beschrieben, das Andeutung von Übergang auf die Sclera zeigt. Verfasser bespricht die Ätiologie und kommt zu dem Schluß, daß das Trauma allein niemals die Ursache ist. Dagegen hält Velhagen den Zusammenhang zwischen einem Sturz auf das Auge und einem Sarkom des Ciliarkörpers für unzweifelhaft525). Die Ausbreitung zweier Ciliarkörpersarkome wird von Coats genau geschildert ${ }^{119}$ ): einmal fanden sich zahlreiche isolierte Tumorzellen in den Bindegewebslücken der Ciliarfortsätze und der Iris, ebenso auf der Irisvorderfläche und der Hornhauthinterwand, sowie in der hinteren Kammer. Verfasser läßt es unentschieden, ob die Propagierung der Zellen durch den Lymphstrom oder durch aktive Wanderung stattfindet. Auch in seinem zweiten Fall, wo die Geschwulst in die Fontanaschen Räume und den Schlemmschen Kanal eingedrungen war, fanden sich freie Sarkomzellen. Denselben Umstand erwähnt Werncke in seinem Fall, wo sich der Tumor nach hinten in die Aderhaut, nach vorn in die Scleralamellen fortgesetzt hatte ${ }^{551}$ ). In dem Falle von Reis war ein melanotisches Ringsarkom durch die vorderen Emissarien nach außen gewachsen und hatte sich unter der Bindehaut weiterverbreitet $^{428}$ ). Den Ursprung der sarkomatösen Wucherung leitet Bergmeister bei seinem Ringsarkom von dem Bindegewebe bzw. den Chromatophoren der Pars plicata und der Iriswurzel her $\left.{ }^{56}\right)$. Auf nekrotische Vorgänge im Tumor, die sich infolge der meist einsetzenden intraokularen Drucksteigerung zeigen, weist Herrenschwand hin ${ }^{240}$ ). Das Glaukom tritt bei Ringsarkom ein, weil die Iris sarkomatös und wie bei Irisatrophie nicht mehr fähig ist, das Kammerwasser abzufiltrieren (Ha mburger). In Ischreyts Fall fehlte ausnahmsweise die Drucksteigerung ${ }^{269}$ ). - Die Sarkome können verhältnismäßig langsam wachsen $^{287},{ }^{14}$ ), ihre Diagnose ist häufig sehr schwer, sei es wegen der bestehenden iritischen Veränderungen ${ }^{13}$ ), sei es wegen der pseudoiritischen Erscheinungen infolge diffuser sarkomatöser Infiltration ${ }^{241}$ ). - Einen Fall, der klinisch für eine Epithelgeschwulst gehalten worden war, erwähnt Akatsuka ${ }^{7}$ ), die Dia- 
gnostik behandelt Bane $\left.{ }^{45}\right)$, über makulare Veränderungen im Frühstadium des Sarkoms sprechen Teissier et Onfra $\mathrm{y}^{\mathbf{5 0 3}}$ ), kas uis tis che Beiträge liefern Agnesworth ${ }^{5}$ ), Hepburn ${ }^{239}$ ), Castelain ${ }^{102}$ ), Luedde ${ }^{333}$ ), Wes cott ${ }^{553}$ ), Coover ${ }^{127}$ ). Ein Fibrosarkom erwähnt Maxson ${ }^{346}$ ), ein Leukosarkom Puscariu ${ }^{417}$ ), Juler bringt die histologische Beschreibung eines Rundzellensarkoms $\mathrm{s}^{275}$ ). Im Falle Heitmanns lag klinisch ein Melanosarkom vor, histologisch war jedoch Gumma nicht mit Sicherheit auszuschließen ${ }^{237}$ ). Einen besonderen Tumor, den er als Endotheliom ansprechen möchte, und der Ähnlichkeit hat mit den von Versca y beschriebenen, von der Dura ausgehenden Geschwülsten, erwähnt Walds tein ${ }^{534}$ ). Es waren spindelige und rundliche Zellen mit bläschenförmigem Kern vorhanden, die in einem feinen Bindegewebsnetzwerk dicht aneinander gelagert waren, ohne Züge oder Balken zu bilden. - Von e pi thelialen Neubildungen handeln folgende Arbeiten: Meller berichtet über eine solche, die Iris und Ciliarkörper völlig ersetzt hatte ${ }^{351}$ ). Sie war hervorgegangen aus einer entzündlichen Wucherung und zeigte einen cylindromatösen Bau und vereinzelt auch Pigment. Ihr Wachstum war infiltrierend und zerstörend. Fuchs erwähnt einen Tumor des retinalen Epithels, der wahrscheinlich vom Ciliarkörper oder auch von der Iris ausging $\left.{ }^{191}\right)$. Histologisch ahmte er die embryonale Retina nach. Auch der von Märtens mitgeteilte Tumor dürfte hier genannt werden ${ }^{341}$. Die ausführliche Beschreibung einer ähnlichen Geschwulst bei einem 4 jährigen Kinde gibt Velhage $n^{526}$ ). Sie setzte sich aus zweierlei Gewebsarten zusammen: 1. epitheliale Bänder aus Zylinderzellen, die unregelmäBige Hohlräume begrenzten. Diese epithelialen Bildungen hatten Ähnlichkeit mit den von Wintersteiner bereits 1897 beschriebenen „Rosetten"564). Das zweite Gewebe bestand aus feinsten, stark lichtbrechenden Fäserchen mit dazwischen gelagerten mittelgroßen Kernen ohne Protoplasmaleib. Dieses Faserwerk wurde für neugebildetes, gliöses Gewebe gehalten. Die epithelialen Bildungen hatten größte Ähnlichkeit mit embryonaler Netzhaut. Das ganze Bild erinnerte an das von Ströbe in seiner ,Entstehung und Bau der Gehirngliome" gegebene, sowie an das, welches Rose nthal in seiner Arbeit über ,,eine eigentümliche mit Syringomyelie komplizierte Geschwulst des Rückenmarkes" bringt. Nach Velhagen besteht eine entwicklungsgeschichtliche Analogie zwischen den Zellauskleidungen der Hirnhöhlen und den Zylinderzellen der Ora serrata und der Pars ciliaris retinae. Verfasser nimmt in seinem Fall eine angeborene Anomalie an, wofür auch das jugendliche Alter des Patienten spricht. - Ein primäres Carcinom, das von den Epithelien der Ciliarfortsätze seinen Ursprung genommen hatte, beschreibt Neeper ${ }^{370}$ ). Endlich sei ein metastatisches Carcinom erwähnt, das Le plat bei einem Mammakrebs fand ${ }^{318}$ ).

\section{Tumoren der Chorioidea.}

Wie bei den Geschwülsten der Iris und des Ciliarkörpers, so nehmen auch hier die Arbeiten über das Sarkom den überwiegenden Teil ein. Die Entstehung desselben sowie des Pigmentes erregt das Interesse mehrerer Autoren. Insbesondere ist es Fuchs, der durch Beobachtung von kleinsten Aderhautsarkomen zu dem Schluß kommt, daß sie in den äußeren Schichten, in der der großen Gefäße, von den Chromatophoren ihren Ursprung nehmen $\left.{ }^{189},{ }^{190},{ }^{192},{ }^{194}\right)$. Und zwar sowohl die pigmentierten als auch die unpigmentierten Sarkome. Meist sind die Zellen spindelförmig. Fuchs geht dann weiter auf die Ausbreitung des Tumors und die Entstehung des Pigmentes ein. Die Glasmembran der Chorioidea wird durchbrochen, dann folgt Abhebung der Netzhaut bzw. Spaltung derselben in der Zwischenkörnerschicht ${ }^{194}$ ). Was die Pigmentierung betrifft, so findet sich in den Zellen des Sarkoms Melanogen, aus dem sich durch Einwirkung eines Fermentes 
Pigment bildet. Nach Fuchs ist dieser Vorgang keine Altersfunktion der Zelle. Die Ursache ist unbekannt; vielleicht ist sie zu suchen in der Berührung mit nekrotischen Massen oder der Lage der Zellen an der Oberfläche. Auch die freien Pigmentzellen stammen nicht vom Pigmentepithel ab, sondern sind wahrscheinlich Sarkomzellen, welche reichliche Nährstoffe in Pigment umwandeln [Überernährung $\left.{ }^{189}\right)$ ]. Für das freie Pigment nimmt von Szily einen ähnlichen Entstehungsmodus an nach seinen Untersuchungen an Wirbeltierembryonen und in Aderhautsarkomen ${ }^{499}$ ): Gewisse Zellen vermögen während der Mitose Teile ihres Chromatins an das Cytoplasma abzugeben. Die Umwandlung dieser ausgestoßenen Chromatinmasse (Chromidien) in Pigment erfolgt unter dem Einfluß von Fermenten (Tyrosinase). Zu ähnlichen Resultaten über die Bildung der Sarkomzellen und des Pigmentes kommen Arganaraz ${ }^{26}$ ) und Lo Cascio ${ }^{98}$ ); dieser hält es für identisch mit dem Augenpigment. Wie F uchs so sind auch Ko moto ${ }^{295}$ ) und Rumszewicz ${ }^{449}$ ) der Ansicht, daß die Leukosarkome nur Anfangsstadien der Pigmentgeschwülste sind. Dieser Auffassung schließt sich auch Velhagen an, der in einem Augapfel zwei Chorioidealsarkome fand, die nur durch entzündlich infiltrierte Aderhaut voneinander getrennt waren. Er betrachtet das mehr Pigment enthaltende Rundzellensarkom als primären, das Spindelzellensarkom, das auch sonst einfacher gebaut war, als metastatischen Tumor ${ }^{527}$ ). Birch-Hirschfeld weist darauf hin, daß unter Melanosarkomen nicht nur die Tumoren verstanden werden, die ihren Ursprung von normalerweise pigmenthaltigen Zellen herleiten, sondern auch die Geschwïlste, welche strenggenommen nur Sarkome mit Herden von Blutpigment sind ${ }^{68}$ ). An 3 Fällen zeigt er, wie kompliziert die Verhältnisse sein können. Andere Arbeiten über beginnende Sarkome liegen vor von $\mathrm{Fuchs}^{190}$ ), Ginsberg ${ }^{207}$ ), Wagenmann ${ }^{531}$ ). Im weiteren Verlauf des Aderhautsarkoms interessiert $u$. a. besonders das Verhalten der Netzhaut ${ }^{368}$ ). Während meist A motio eintritt, so wird ausdrücklich auf ihr Fehlen hingewiesen von Lodberg ${ }^{327}$ ) und Berg ${ }^{55}$ ): Die Retina war in beiden Fällen vom Tumor durchbrochen worden. Von einer Degeneration der Elemente der über den Tumor hinwegziehenden Netzhaut spricht K raff $\mathrm{t}^{298}$ ). Endlich kommt eine S paltung der Retina vor, ohne daß sie von der Geschwulst durchwuchert ist, wofür Ballaban eine Erklärung $\mathrm{zu}$ geben versucht $\left.{ }^{44}\right)$. In dem Fall von Kadletz war die Netzhaut ebenfalls in zwei Blätter gespalten ${ }^{278}$ ); nur die Gehirnschicht überzog den Tumor. Kadletz führt dieses Verhalten auf die verschiedene Elastizität der einzelnen Schichten infolge ihrer Struktur zurück. - - Die bald einsetzenden entzündlichen Veränderungen im Auge werden von den meisten Autoren auf nekrotische Vorgänge im Tumor zurückgeführt. Die Toxine, die dabei gebildet werden, machen Iridocyclitis $\left.{ }^{189}, 427\right)$. Eine Tenonitis derselben Ätiologie beschreibt Nobuo Inou y $\mathrm{e}^{268}$ ). Dagegen betont Mi ya shita, daß die Entzündung der Tenonschen Kapsel sich schon bei beginnendem Aderhautcarcinom finden kann, wo noch keine Nekrose vorhanden ist ${ }^{359}$ ); er macht vasomotorische und neuritische Reize für die Tenonitis verantwortlich. Dieser Entzündung kann unter Umständen diagnostische Bedeutung zukommen. Hierher gehört auch ein Fall von Aderhautsarkom des einen und sympathischer Entzündung des anderen Auges, den Meller ausführlich beschreibt ${ }^{350}$ ). Der Tumor zeigte nekrotische Bezirke, die nicht entarteten Teile der Chorioidea trugen die Merkmale der sympathisierenden Entzündung. Eine Eingangspforte für pathogene Keime war nirgends nachweisbar. Dieser Umstand der intakten Bulbushülle ließ das Hervorrufen der sympathischen Entzündung immerhin rätselhaft erscheinen. Meller nimmt eine endogene Infektion an bei verminderter Widerstandsfähigkeit des Sarkomauges. Eine Neuritis optica infolge nekrotischer Tumorveränderungen teilt Pálich-Szánto mit ${ }^{384}$ ). Doch können auch entzündliche Ver- 
änderungen völlig fehlen trotz ausgedehnter Nekrose $\left.{ }^{366}\right)$. Andererseits sind nekrotische Vorgänge im Tumor als nicht ungünstige Umstände anzusprechen; so werden z. B. nach Ehrlich durch Resorption von zerfallenden Tumormassen Antikörper gebildet, und eine aktive Immunität tritt ein $\left.{ }^{306}\right)$. Fuchs spricht von einer Selbstheilung durch Nekrose unter Schrumpfung des Bulbus ${ }^{189},{ }^{192}$ ). Was die Entstehung des Chorioidealsarkoms anlangt, so wird wie auch sonst das Trauma verantwortlich gemacht ${ }^{23}$ ). Dagegen lehnt Meller in seinem Fall den Zusammenhang zwischen beiden ausdrücklich $\left.a b^{353}\right)$. - Die Diagnose wird in einer Reihe von Arbeiten behandelt. In ausführlicher Weise bespricht Fo ster Moore die Differentialdiagnose gegenüber benignen Melanomen ${ }^{363}$ ), und Ment. berger erwähnt unter Zufügung eines eigenen die Fälle der Literatur, die diagnostische Schwierigkeiten boten ${ }^{357}$ ). Auch der Fall von Weishau ut war schwer zu diagnostizieren ${ }^{545}$ ); nach Anfällen von Iritis waren schwere Blutungen im Augeninneren und absolutes Glaukom aufgetreten. Anatomisch fand sich ein Melanosarkom der Aderhaut. Selenkows ky bringt einen Fall von Spindelzellen-, von Leuko- und ein alveoläres Sarkom und knüpft daran Bemerkungen über die Diagnose ${ }^{475}$ ). Allan Greenwood ${ }^{217}$ ), Lindahl ${ }^{321}$ ), Clapp $p^{113}$ ) liefern Beiträge zur Frage der transscleralen Durchleuchtung. - Die Prognose ist nach Arganaraz sehr schlecht, wenn auch Rezidive und Metastasen sehr langsam auftreten $^{27}$ ). Besonders bösartig sind die Flächensarkome $\left.{ }^{270}\right)$. Weitere prognostische Bemerkungen bringt $\mathrm{Fage}^{\mathbf{1 7 0}}$ ). - Das Aderhautsarkom kommt nach den vorliegenden Arbeiten in allen Lebensaltern vor; I w u mi beobachtete ein Leukosarkom bei einem $2^{1 / 2}$ jährigen Kinde ${ }^{276}$, und Lawford und Greeves sahen ein Sarkom der Chorioidea bei einem Mann von $90^{3 / 4}$ Jahren, das höchste zur Beobachtung gelangte Alter ${ }^{311}$ ). - Über eine Spaltung der Chorioidea in zwei Blätter bei einem Spindelzellensarkom berichten Pons Marqués und Menacho, welche diesem Umstand günstige prognostische Bedeutung zuschreiben ${ }^{407}$ ). Ein Melanosarkom mit Pigmentfleck auf der Iris wird von Albanese mitgeteilt, der mikroskopisch keinen Zusammenhang zwischen beiden nachweisen konnte $^{8}$ ). Ungewöhnliche klinische Erscheinungen in einem Fall von Aderhautsarkom erwähnt Green ${ }^{216}$ ), welchen Fall Alt mikroskopisch beschreibt ${ }^{19}$ ), ebenso Fejêr $\left.{ }^{176}\right)$. Während es im Verlauf von intraokularen Tumoren gewöhnlich zur Drucksteigerung kommt, fand sich in 3 Fällen von Chorioidealsarkom, die Franz beschreibt, $\mathrm{H}$ y potonie ohne entzündlich atrophische Veränderungen ${ }^{18 \overline{3}}$ ). Dagegen bestanden Glaskörperschrumpfung, Netzhautablösung, Erhaltensein des Kammerwinkels, Offensein des Schlemmschen Kanals. Ob ein verstärkter Abfluß des Kammerwassers zur Hypotonie führte, wird nicht entschieden. Endlich sei ein Fall von Cornealr u ptur genannt, den Weidler erörtert ${ }^{544}$ ). Einer statistischen Verwertung unterzieht Lemberg 31 Fälle aus der Zeit von 1890 bis 1919317). Kasuistische Beiträge liefern Bentzen ${ }^{53}$ ), Ring ${ }^{433}$ ), Wells ${ }^{546}$ ), Wescott ${ }^{55}$ ), Maxs on $\left.{ }^{346}\right)$, Gines to us ${ }^{205}$, Heed ${ }^{232}$ ), Lediard ${ }^{315}$ ), Teillais ${ }^{502}$ ), Botteri $\left.{ }^{81}\right)$, Weekers und Mouchet $\left.{ }^{539}\right)$, Zentmayer $\left.{ }^{574}\right)$, Castresana ${ }^{103}$ ), Kadinsky ${ }^{277}$ ), Stark ${ }^{485}$ ), Holmes und Greeves ${ }^{254}$ ), Duvigneaud und Duclos ${ }^{152}$ ), Reiche $e^{425}$ ), Kei per ${ }^{282}$ ), Schneider ${ }^{460}$ ), Jackson ${ }^{259}$ ), Schridde ${ }^{463}$ ), Aurant und Genet ${ }^{35}$ ), Woodward ${ }^{570}$ ), Turner ${ }^{517}$ ), Nettleship ${ }^{372}$ ), Pose $y^{412}$ ), Schieck ${ }^{455}$ ), Neuburger ${ }^{373}$ ), Sedwick ${ }^{43}$ ), Roll ${ }^{438}$ ), Jackson und Fir mof $\mathrm{f}^{260}$ ). - Im Vergleich zum pigmentierten Sarkom befassen sich nur wenig Arbeiten mit dem Le u kosarkom. Bereits erwähnt wurde die Ansicht darüber

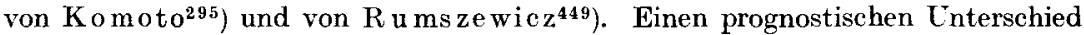
zwischen dem ,weißen und schwarzen" Sarkom will Hirschberg nicht gemacht haben; er beobachtete 3 Fälle von Leukosarkom 15, 19, ja sogar 28 Jahre, die nach Enucleation rezidiv- und metastasenfrei geblieben waren ${ }^{249}$ ). Einen Fall, 
bei dem die Papilla nervi optici beteiligt war, beschreibt $P$ errod ${ }^{393}$ ), einen anderen mit gleichzeitigem Bestehen eines Lippenepithelioms Valentine, der das Vorkommen beider Geschwülste bei demselben Patienten für Zufall hält ${ }^{520}$ ). Bemerkenswert ist der von Galezowski mitgeteilte Tumor, der zunächst für ein Gu m ma angesehen worden war ${ }^{197}$ ). Der Fall $\mathrm{I}$ w u $\mathrm{m}$ is wurde bereits genannt ${ }^{276}$ ), Chevalier bespricht die Symptome der Frühdiagnose ${ }^{111}$ ), klinische bzw. histologische Beschreibungen geben Risle $y^{436}$ ), Bonnefo $\left.y^{78}\right)$, Teulier ès $\left.{ }^{506}\right)$, Wain stein ${ }^{533}$. Die anatomische Cntersuchung eines Tumors, der sich längs den hinteren Ciliararterien ausgebreitet und außerhalb des Bulbus einige Knötchen gebildet, sowie auf kurze Strecke den Sehnerven infiltriert hatte, ergab nach Treacher Collins ein Endothelio ${ }^{337}$ ). Ein anderes Endotheliom, gleichfalls mit Beteiligung des Nervus opticus, erwähnt McKa $\mathrm{y}^{281}$. Von den größeren Gefäßen der Aderhaut ging ein Tumor aus, den Alt als Peritheliom bezeichnete $\left.^{16}\right)$. - Über ein metastatisches Aderhautsarkom liegt nur die Arbeit Fehrs vor, der das ophthalmoskopische Bild mitteilt ${ }^{175}$ ).

In den vorliegenden Arbeiten über das Carcinom der Chorioidea handelt es sich ausschließlich um sekundäre Neubildungen. Und zwar wird nach L1lmann meist das Mammacarcinom als primärer Tumor angegeben ${ }^{518}$ ). Bei der Häufigkeit dieses sind jedoch Aderhautmetastasen selten. Wegen allgemeiner Kachexie werden die Augen in vivo selten untersucht; es handelt sich also meist um Zufalls-Sektionsbefunde [anläßlich einer Untersuchung von Carcinomleichen fand Greeff dreimal Aderhautkrebs $\left.{ }^{215}\right)$ ]. Im feineren Bau ähnelt der Sekundärtumor der Muttergeschwulst; er ist nur weniger differenziert. Regressive Veränderungen sind häufig; sie werden hervorgerufen durch Blutungen in den Tumor oder sind als Drucknekrosen aufzufassen. Im Gegensatz zum Sarkom kommt, weil sekundär, Doppelseitigkeit vor; Iridocyclitis findet sich nicht so häufig wie bei jenem. Die Metastasierung geschieht durch die hinteren kurzen Ciliararterien auf embolischem Wege. Zu ähnlichen Ergebnissen über Bau und Ursprung des metastatischen Carcinoms kommt Steichele $\left.{ }^{486}\right)$. Dagegen weist Gutmann in seinem Fall ausdrücklich auf das Bestehen einer kleinzelligen Infiltration von Sclera, Aderhaut, Iris (Uveitis) hin ${ }^{224}$ ). Auch Hegener spricht von einer Iritis im Zusammenhang (mit der Tumormetastase ${ }^{234}$ ). Histologische Befunde bringen die Arbeiten von Aris $w_{\mathbf{w}^{31}}$ ), Ishihara $\left.{ }^{272}\right), \mathrm{Ask}^{32}$ ); bei diesem handelte es sich um Metastasen in beiden Augen bei Prostatacarcinom. An Hand von 2 Fällen behandelt Hirsch die prognostische Bedeutung des metastatischen Aderhautcarcinoms ${ }^{\mathbf{2 6}}$ ). Igersheimer berichtet über therapeutische Versuche bei doppelseitigem Aderhautkrebs ${ }^{267}$ ): Serumbehandlung nach Abderhalden blieb ohne Erfolg. Unter Röntgentiefenbestrahlung traten gewisse regressive Veränderungen in der Geschwulst auf, so daß im gleichen Falle immerhin ein Versuch damit gerechtfertigt erscheint. Kasuistische Beiträge liefern $\mathrm{Harms^{230 }}$ ), Franke ${ }^{184}$ ), Weeks ${ }^{541}$ ), Demaría und Arganarázitr), Meesmann ${ }^{349}$ ), Clausen ${ }^{144}$ ). Noyes $\left.{ }^{376}\right)$.

\section{Tumor'en der Retina.}

Der Häufigkeit des Vorkommens entsprechend ist in der weitaus größten Zahl der vorliegenden Arbeiten das Gliom Gegenstand der Besprechung. Die Entstehung nimmt das Interesse mehrerer Autoren in Anspruch. Und zwar kommen fast alle zu dem Ergebnis, daß dem Gliom eine Keimversprengung, d. h. eine Fntwicklungsstörung zugrunde liegt $\left.{ }^{564},{ }^{313},{ }^{58},{ }^{542}\right)$. Der Ansicht Deutsch. manns, der ein atypisches Gliom seinen Ursprung vom Pigmentepithel der Retina, d. h. also nicht von embryonalen, sondern von fertigen Zellen nehmen läBt, wird denn auch entgegengetreten von Reis, welcher immer die gewucherten 
Pigmentepithelzellen von den Gliomzellen unterscheiden konnte ${ }^{143},{ }^{428}$ ). Auch Reis ist der Auffassung, daß das Gliom aus versprengten Neuroblasten entsteht. Die Versprengung kann natürlich in die verschiedensten Netzhautschichten erfolgen. Vom ektodermischen Ursprung des Glioms spricht Guglia netti ${ }^{222}$ ). Auf ex perimentellem Wege kommt von Szil y zu denselben Resultaten über die Genese des Glioms ${ }^{500}$ ); besondere Bedeutung schreibt er den von Hirsch berg schon 1869 gesehenen und von Wintersteiner als Rosette $n$ bezeichneten Gebilden zu $\left.{ }^{248},{ }^{564}\right)$. Den Mechanismus ihrer Entstehung sucht in einer ausführlichen Besprechung Calderaro zu erklären ${ }^{93}$ ). Interessant sind die Anschauungen Wehrlis über die auslösende Ursache der Gliombildung ${ }^{542}$ ): durch intrapartielle direkte und indirekte Blutungen und Zerreißungen der Retina wird eine regenerative Zellteilung hervorgerufen. Natürlich muß die Läsion nicht normale, sondern von ihrem Mutterboden losgetrennte, den Keim der Malignität in sich tragende, embryonale Elemente treffen. Was die verschiedenen Formen des Glioms anlangt, so unterscheidet Delmonte auf Grund seiner mikroskopischen Beobachtungen von 7 Fällen 3 Typen: das einfache, das tubuläre Gliom, das Gliosarkom ${ }^{139}$ ). Für das tubuläre nimmt er, da Rosetten fehlen, das Bindegewebe als Ursprung an. Von einem nicht einheitlichen Aufbau des Glioms sprechen auch Verme ${ }^{586}$ ) und Casali ${ }^{97}$ ), und die histologischen Befunde von Peschel ${ }^{394}$ ) und Monauni ${ }^{360}$ ) scheinen diese Auffassung zu crhärten. Einen weiteren Beitrag zur Anatomie des Glioms liefert Schneider $\left.{ }^{5} 8 \tilde{y}\right)$. Für die Heredität des Glioms bringen Belege de Goûvéa ${ }^{213}$ ), Cas par ${ }^{101}$ ), Griffith ${ }^{220}$, der 6 Fälle aus der Literatur anführt, Traquair $\left.{ }^{516}\right)$. Auf die Doppelseitigkeit, die nach den statistischen Angaben von Adam $^{1}$ ) in $8,5 \%$ der Fälle vorkommt, weisen hin Alexander ${ }^{11}$ ), Stoll $\left.{ }^{196}\right)$, Lowzow ${ }^{331}$ ), Siegrist478), in dessen Fall sich die Geschwulst ausschlieBlich in den Zwischenscheidenräumen des Sehnerven bis zur anderen Papille fortgepflanzt hatte, Fleming ${ }^{181}$ ), Maghi ${ }^{335}$ ). Bei diesem handelte es sich um eine 20jährige Patientin, das höchste bisher beobachtete Alter für das Vorkommen des Glioms. In dem Knie perschen Falle war auf dem zweiten gliomatösen Auge, das nicht enucleiert wurde, Atrophie aufgetreten ${ }^{292}$ ). Auch sonst wird Phthisis bulbi bei Gliom erwähnt ${ }^{125},{ }^{532},{ }^{183}$ ). Im ersten Fall war eine Blutung in die Vorderkammer vorausgegangen, in den beiden letzten Fällen ist die Schrumpfung wohl als Ausgang einer plastischen Iridocyclitis aufzufassen, worauf bereits Hirschberg und Wintersteiner in ihren grundlegenden Arbeiten hingewiesen hatten ${ }^{248},{ }^{564}$ ). Über sekundäre Entzündung beim Netzhautgliom berichtet auch Redicker ${ }^{423}$ ). Hornhaut und Sclera leisten den durch die absterbenden Tumorzellen produzierten Toxinen, welche zur Cveitis führen, sowie der Invasion des Tumors lange Widerstand; rupturiert jedoch, infolge des hohen Druckes beim Wachsen der Geschwulst die Descemetsche Membran, so können die Toxine ins Hornhautparenchym eindringen und Schädigungen verursachen $\left.{ }^{61}\right)$. Die Veränderungen des Glaskörpers, welche Trantas erwähnt, dürften auch hierher gehören ${ }^{514}$ ). Ausgedehnte regressive Veränderungen werden im Gliom nicht selten beobachtet $^{419}$ ); diese können so weit gehen, daß es zu einer Art S pontan heil ung kommt, die nach Meller durch einen unbekannten Faktor hervorgerufen wird ${ }^{352}$ ). Dauerheilung hält Purtscher für sehr zweifelhaft\$16); eine 30 jährige Patientin, die Netzhautveränderungen zeigt, welche $\mathrm{F}$ uchs für Gliom hält, macht Dauerheilung jedoch wahrscheinlich. Anatomische Belege für zurückgebildete Gliome, die noch Spuren charakteristischen Gewebes erkennen lassen, geben de Kleijn284) und Lindenfeld ${ }^{322}$ ). - Die Diagnose kann Schwierigkeiten machen infolge der im Verlauf des Glioms einsetzenden ,Iridocyclitis“. So bringt Behr einen Fall, der unter dem Bilde einer primären, knötchenförmigen, tuberkulösen Iritis verlief ${ }^{49}$ ). Nach der Enucleation wurde Gliom festgestellt, die Irisknoten, das Hypo- 
pyon sowie die Descemetbeschläge waren intraokulare Geschwulstmetastasen. Die Irisknoten und die Descemetveränderungen gelten übrigens als extrem seltene Befunde. Zwei Präparatevon Retinitis ex sudativa, die Sidney-Stephenson zeigte, hatten klinisch als Gliom imponiert ${ }^{492}$ ). Da das sog. Pse udogliom gar nicht so selten ist, so verlangt Paders te in unbedingte Sicherstellung der Diagnose für statistische Erhebungen $\left.{ }^{382}\right)$. - Die Prognose quoad vitam wird nach de Kleijn und Gerlach häufig zu schlecht gestellt ${ }^{285}$ ), und (asali ${ }^{97}$ ) sowie Genet ${ }^{201}$ ) kommen zu der Ansicht, daß die reinen, von den Netzhautelementen selbst ausgehenden Gliome weniger bösartig sind als die Mischformen. - In der Therapie spielt die Frage der Bestrahlung besonders wegen der häufigen Doppelseitigkeit eine Rolle. Axenfeld hatte günstige Erfolge mit Röntgenstrahlen $\left.{ }^{39},{ }^{40}\right)$. Auch Uhthoff gibt diesen den Vorzug vor dem Mesothorium ${ }^{519}$ ); erstere wirken tiefer und mehr elektiv auf das Tumorgewebe). Er sowie Dimmer besprechen die Fälle der Literatur über Rückbildung und Strahlentherapie $\left.{ }^{146}\right)$. Schönberg sah unter Radium ein Zurückgehen des Tumors bei doppelseitigem Gliom ${ }^{41}$ ). Kasuistische Beiträge liefern Stiere ${ }^{493}$ ), Ohnacker ${ }^{379}$ ), Ayre s ${ }^{37}$ ), Alexander ${ }^{12}$ ), Lodberg ${ }^{328}$ ), Siegris $\left.t^{49}\right)$, z ur Nedden ${ }^{369}$ ), Reeder und Darling ${ }^{124}$ ), Camis on ${ }^{94}$ ), Gleeson ${ }^{210}$ ).

Über andere Geschwülste der Netzhaut liegen nur wenige Arbeiten vor. Elschnig teilt einen Fall mit, wo dicht vor der Papilla nervi optici eine lappige Geschwulst aus spindelförmigen Zellen saß167). Ein anderer Tumor bestand aus dichtfaserigem, in bandförmigen Zügen angeordneten Gewebe mit epitheloiden Zellen, gliakernähnlichen Kernen und großen Convoluta z. T. obliterierter Gefäße. Elschnig nimmt an, daß die Geschwulst von Zellen des inneren Blattes der sekundären Augenblase in der Gegend der Ora serrata abstammte, aus der Glia-, Nervenfaser- und Ganglienzellen entstehen. Er glaubt, daß bei der Entwicklung Netzhautzellen undifferenziert geblieben sind, die zu abnormer Proliferation kamen. Elschnig nennt diesen Tumor Neurinoma (Neurocy toma) retinae. In einer weiteren Arbeit beschreibt er einen Tumor, den er vom Bindegewebe der Zentralgefäße und deren Zweige ausgehen läßt $\left.{ }^{166}\right)$. Ginsberg teilt ein Angiogliom mit ${ }^{208}$, Walker ein Angiosark om bei einem 4 jährigen Knaben ${ }^{535}$ ), Schieck einen ebenfalls zu den Angiosarkomen gehörigen Tumor, der jedoch nicht vom Endothel der Gefäße - dieses war völlig intakt - sondern rom Perithel seinen Ausgang genommen hatte ${ }^{454}$ ). Endlich beschreibt Arisawa ein alveolär-tubulöses E pithelzellencarcinom ausschließlich der Netzhaut bei gleichzeitig bestehendem Bauchtumor $\left.{ }^{30}\right)$. Die Frage wird nicht beantwortet, welches der primäre Tumor war. Wenn die Retina zuerst befallen war, so ist seine Entstehung nur durch eine Zellverlagerung, also kongenital zu erklären. Derselbe Autor bringt noch ein metastatisches Netzhautcarcinom ${ }^{29}$ ).

18. Tumoren der Papilla nervi optici.

Diese Geschwülste sind nach Oloff meist Sarkome und kommen fast immer bei Jugendlichen vor ${ }^{380}$ ). Im Falle Murrays war der mit einem Spindelzellensarkom behaftete Patient allerdings 60 Jahre alt ${ }^{367}$ ). Vasquez-Barrière beschreibt ein Melanosarkom ${ }^{522}$ ) und Krauss ein von den Wänden der Zentralgefäße ausgehendes Angiosarkom bzw. Peritheliom ${ }^{301}$ ). Ähnlichen Ursprung nimmt Sidler-Huguenin bei seinem Endotheliom $a^{477}$ ): er meint, daß sich dasselbe wahrseheinlich aus früher vorhandenen Hyaloidearesten entwickelt hat.

19. Tumoren des Sehnerven.

Eine allgemeine Betrachtung liefern Byers und Gordon ${ }^{92}$ ). An Hand der Literatur gibt $\mathbf{H u d s}$ on eine Einteilung ${ }^{257}$ ), und zwar unterscheidet er 1. eine 
Gliomatose (in der Literatur als Gliom, Myxogliom, Myxom, Myxofibrom, Myxosarkom bezeichnet). Er faßt sie als Wucherung der Glia, nicht als eigentliche Neubildung auf. So werden z. B. nie Rezidive beobachtet. 2. Fibromatosis, die auch nur ein Wuchern des Bindegewebes ist. 3. Endotheliom. Auch Golowin, der die Tumoren in extra- und subdurale (subvaginale) einteilt, bält die Gliomatose $\mathrm{Huds}$ ons für gutartig ${ }^{211}$ ); er spricht sie als eine Ele phantia si s des Sehnerven an. Lnd Thumm will (mit Sattler) den Begriff Myxosarkom durch Fibrom bzw. Myxofibrom ersetzt haben ${ }^{509}$ ). Fast alle als Gliom beschriebenen Fälle sind intradural gelegen und gut abzugrenzen. Dasselbe Verhalten zeigte übrigens auch der von Cohen mit Neuroglioma ganglionicum (Gioblastoma) bezeichnete Tumor ${ }^{121}$ ). Die Glioma lassen sich durch die Krönleinsche Operatior: entfernen; auch wird von einigen Autoren darauf hingewiesen, daß trotz unvollständiger Exstirpation keine Rezidive auftraten ${ }^{330},{ }^{172}, 409,{ }^{497},{ }^{161},{ }^{431}$ ). Kn a p p dagegen betont ausdrücklich, daß auch die Gliome maligner Natur seien ${ }^{290}$ ). Auch das Myxosarkom, das Motoo Segi beschreibt, scheint bösartig gewesen zu sein ${ }^{474}$ ). Anläßlich eines selbstbeobachteten Glioms des Sehnerven registriert Ko yanagi 135 Fälle der Literatur ${ }^{297}$ ); er erwähnt die Ansicht Braunschweigs, der die verschiedenen Tumoren nur für Varietäten einer im wesentlichen gleichen Ge. schwulst mesodermalen Ursprunges hält. Nach ihm ist der Haupttypus das Myxosarkom, nach anderen das Gliom. Das Endotheliom behandeln Ben so ${ }^{52}$ ) und Heed ${ }^{233}$ ), Wessely ein psammöses Endotheliom ${ }^{555}$ ), das als Rezidiv nach Exstirpation intrakraniell weiter wuchs und zum Exitus letalis führte, und Anton ${ }^{25}$ ). Griffith ${ }^{219}$ ), Byers und Gordon ${ }^{92}$ ), Lindenmeyer ${ }^{323}$ ), Zitows$\mathrm{ky}^{580}$ ), Davis $\left.{ }^{136}\right)$, Pollack ${ }^{405}$ ) liefern kasuistische Beiträge.

\section{Tumoren der Orbita.}

Die Mehrzahl der Arbeiten behandelt, der Häufigkeit des Vorkommens entsprechend, das Sarkom. Die verschiedensten Formen werden genannt: Spindelzellensarkome $\left.{ }^{15},{ }^{562},{ }^{115},{ }^{221}\right)$, Rundzellensarkome $\left.{ }^{42},{ }^{392},{ }^{206}\right)$, Riesenzellensarkome ${ }^{187}$ ), Fibrosarkome ${ }^{340},{ }^{228},{ }^{336},{ }^{69}$ ), Alveolarsarkome ${ }^{325}$ ), Myxosarkome ${ }^{325},{ }^{355}$ ), Fibromyxosarkome ${ }^{530}$ ), Myxochondrosarkome ${ }^{584}{ }^{155}$ ), Myosarkome ${ }^{410}$ ), Endotheliome $\left.{ }^{316},{ }^{74},{ }^{507},{ }^{136},{ }^{498}\right)$. Als Ausgangspunkte dieser Tumoren, auf deren langsames Wachstum, Abkapselung und folglich gute Exstirpationsmöglichkeit der Bulbus konnte tejlweise erhalten bleiben ${ }^{169},{ }^{505}{ }^{\text {a }},{ }^{468},{ }^{336},{ }^{377},{ }^{15},{ }^{95}$ ) — von den Autoren verschiedentlich hingewiesen wird, werden angegeben das retrobulbäre Bindegewebe, das Bindegewebe der Muskeln und Nerven, das Periost der Orbita, sowie das der benachbarten Nasen-Nebenhöhlen; auch als Lokalrezidive besonders von entfernten Chorioidealsarkomen sind manche Orbitaltumoren anzusehen ${ }^{\mathbf{5} 75},{ }^{555}$ ). Daß der Augapfel selbst meist frei von Tumor gefunden wird, nimmt nicht wunder, da er bekanntlich einer Invasion großen Widerstand entgegensetzt. Dagegen zeigt er häufig erhebliche Veränderungen infolge der Verdrängung durch den retrobulbären Tumor und der durch ihn geschaffenen Zirkulationsverhältnisse. So erwähnen Birch-Hirschfeld und Siegfried hochgradige Deformität mit sekundärer Faltenbildung der Innenmembranen, Netzhautablösung und Degeneration der Stäbchen- und Zapfenaußenglieder, z. T. auch ihrer Körner, hochgradige venöse Stauung im Sehnerven, in Netz- und Aderhaut, Ablösung der Aderhaut im vorderen Bulbusabschnitt $\left.{ }^{69}\right)$. Auf ähnliche Befunde weist Böhm hin ${ }^{77}$ ). Chronisch-interstitielle Entzündung zeigt der Bulbus in den Fällen von Pose $y^{410}$ ), der dieselbe als eine Schutzmaßnahme auffa $3 t$ gegen die Tumorinvasion, Is ehreyt $t^{2 * 1}$ ), d'Ayrenx et de $S p e v i l l e^{36}$, die auf eintretendes Glaukom aufmerksam machen. Über besonders bösartig verlaufende Fälle berichten $\mathrm{Hade}{ }^{228}$ ), Wood $\left.{ }^{569}\right)$, $\left(\mathrm{de}^{263}\right)$, und zwar handelte es sich hier um ganz junge Kinder. Auch 
angeboren kommt das Orbitalsarkom nach $M a y o u^{347}$ ) und $M a x \operatorname{son}^{346}$ ) vor. Kirk patrik teilt ein doppelseitiges Orbitalsarkom mit $\left.{ }^{283}\right), Z_{\text {iegler }}{ }^{577}$ ), Bere $\mathbf{n s}^{54}$ ), Jackso ${ }^{259 a}$ ) je einen Fall bei einem Neger. Wie sonst so wird auch beim Orbitalsarkom dem Tr a u ma eine Rolle zugeschrieben, sei es für die Entstehung ${ }^{54},{ }^{430},{ }^{420}$ ), sei es für besonders rasches Wachstum eines bereits bestehenden Tumors ${ }^{563}$ ). Remelé bemerkt, daß unter 52l Fällen $42 \mathrm{mal}$ ein Trauma in der Anamnese vorlag430). - An der Hand von Beispielen wird die Diagnose besprochen von de Schweinitz ${ }^{465}$ ) und von Dahms ${ }^{133}$ ); $\mathbf{K}$ uf fler betont bei einem Endotheliom der Orbita die Schwierigkeit der anatomischen Diagnose ${ }^{304}$ ). Die diagnostische Röntgenuntersuchung wird von van der Hoeve besonders bei Osteomen, aber auch bei weichen Tumoren empfohlen ${ }^{250}$ ). - Thera peutische Notizen geben Robert Sattler ${ }^{451}$ ), F üs $\mathrm{ci}^{195}$ ), Hechel ${ }^{231}$ ), welche bei Sarkomrezidiven gute örtliche Erfolge mit Röntgenstrahlen hatten. Auf Grund eines günstigen Erfolges empfiehlt Israelit den Versuch mit einer Inunctionskur ${ }^{273}$ ). Kasuistische Beiträge zum Orbitalsarkom liefern de Schweinitz und $\mathrm{Maxwell^{470 }}$ ), Webste $\mathrm{r}^{537}$ ), Golowin ${ }^{212}$ ), Weidler ${ }^{543}$ ), Week ${ }^{540}$ ), Charlet ${ }^{109}$ ), Klinedinst ${ }^{286}$ ), Kr üd. ner $\left.{ }^{303}\right)$, Jackson ${ }^{259}$ ). Im AnschluB an das Sarkom seien noch die besonderen Fälle von $\mathrm{Alt}^{20}$ ) und von Wigods k $\mathrm{y}^{561}$ ) erwähnt: ersterer beschreibt ein orbitales Peritheliom bei gleichzeitig bestehendem intraokularen Sarkom; er hält beide für verschiedenartige Tumoren, die nichts miteinander zu tun haben. Letzterer bringt ein Gliom der Orbita, das sich wahrscheinlich per continuitatem vom Gehirn aus entwickelt hatte. Den seltenen Fall eines Ly m phosarkoms erörtert $\mathrm{Rumbaur}{ }^{48}$ ). Da lymphadenoides Gewebe in der Orbita bisher nicht nachgewiesen wurde, nimmt er eine embryonale Keimversprengung zur Erklärung der Entstehung an. Ein stellenweise sarkomatös umgewandeltes L y $\mathrm{m}$ phangio $\mathrm{m}$ erwähnt Fehr ${ }^{174}$ ). - Was die metastatischen Tumoren anlangt, so befaßt sich die Dissertation von Schmiedt mit ihnen ${ }^{459}$ ). Von metastatischen Sarkomen werden zwei erwähnt, die beide von einem primären Nebennierentumor ausgingen $\left.{ }^{398},{ }^{555}\right)$. Die Orbitalmetastase von einem echten Nebennierentumor bei einem jungen Kinde beschreibt $Q$ uaken boss ${ }^{418}$ ); er fand die charakteristische Rosettenanordnung der Zellen, entsprechend den embryonalen Nervenzellen der Nebennieren. Einen ähnlichen Befund konnte Wessely bei seinem primären Nebennieren-Neuroblastom erheben ${ }^{556}$ ).

Über die selteneren e pithelialen Neubildungen der Orbita finden sich nur wenige Arbeiten. Eine allgemeine Betrachtung stellt van Duyse $a^{157}$ ). In den meisten Fällen handelt es sich um metas ta tis che Carcino me $e^{202},{ }^{312},{ }^{476},{ }^{124}$; letzterer hebt hervor, daß der primäre Tumor meistens in der Mamma sitzt. In anderen Fällen sind die Orbitalcarcinome fortgeleitete: von der $\mathrm{Hy}$ pophyse ging wahrseheinlich das aus kubischen Epithelzellen bestehende, doppelseitige Carcinom Birch-Hirschfelds aus ${ }^{67}$ ), das anfangs einen entzündlichen Proze $B$ vortäuschte, und von den Nebe $n h$ öhlen der Nase ein Carcinoma cylindromatodes von Barbezat von les Bayards ${ }^{47}$ ). Besonders bösartig durch seine raschen wiederholten Rezidive war der Fall von van Duyse et $A$ ubinea ${ }^{158}$ ), während Rollet davon spricht, daß die Prognose der primären Orbitalcarcinome meist nicht so schlecht ist wie angenommen wird $\left.{ }^{439}\right)$. Über ein von der lateralen und unteren Wand der Orbita ausgehendes Carcinom berichtet Knapp ${ }^{291}$ ), Posey bringt ein Ule us rodens der Orbita ${ }^{411}$ ), Risley beschreibt die plastische Operation bei einem Epitheliom ${ }^{435}$ ), Dupuys-Dutemps ${ }^{151}$ ) und Wirtz ${ }^{566}$ ) liefern kasuistische Beiträge. Endlich seien zwei mit Metastasenbildung einhergehende bösartige Myeloc ytome erwähnt ${ }^{364},{ }^{314}$ ), sowie der ,orbitale Tumor" Elliots, bei dem Augengewebe nicht mehr zu erkennen war $^{162}$ ), und der ,,retrobulbäre Tumor" Poseys ${ }^{413}$ ). 


\section{Andere intraokulare Tumoren.}

Hier seien die Arbeiten genannt, deren Crsprung aus den Arbeiten nicht ersichtlich ist, sowie die Abhandlungen allgemeiner Art. Eine Literaturangabe findet sich bei Viterbi ${ }^{529}$ ); die Symptomatologie behandeln Galezows ki ${ }^{196}$ ) und Marin A mat ${ }^{24}$ ). Über das Trauma als Entstehungsursache sprechen Zets che und Bailoni $\left.{ }^{576},{ }^{43}\right)$ : jener lehnt den direkten Zusammenhang zwischen Trauma und Tumor in seinem Fall $a b$, wo es sich um einen nach einem Trauma phthisisch gewordenen Bulbus handelte. Fraglich bleibt jedoch, ob die Phthisis nicht ein begünstigendes Moment für die Tumorbildung bedeutet. Bailoni hält einen Zusammenhang bei genauer Beachtung aller Faktoren für zweifelhaft. Als Besonderheiten bringen Duclos und Sabot ${ }^{149}$ ) eine intraokulare Mischges chw uls t von Melanosarkom und Peritheliom, Alt ${ }^{21}$ ) ein gefäBreiches Spindelzellensarkom mit Knochen- und Kavernenbildung, Stock ${ }^{494}$ ) ein Myelom ebenfalls mit Knochenbildung. Lohfeld t teilt einen Fall von Melanosarkom mit, bei dem als erstes Symptom eine Scleritis auftrat ${ }^{329}$ ). Eine starke örtliche und allgemeine Reaktion a uf Tuberkulin zeigte ein Tumor von Charles ${ }^{108}$ ). Während der Tuberkulintherapie trat wieder eine Reaktion bei $10 \mathrm{mg}$ auf. Bei der nun vorgenommenen Enucleation stellte sich der Tumor als typisches Spindelzellensarkom heraus. Charles nimmt an, daß neben dem Tumor eine Uvealtuberkulose bestand, welche die örtliche Reaktion bedingte. Über die Chirurgie und pathologische Anatomie der Endotheliome spricht Rosenberg ${ }^{445}$ ), über gute Erfolge mit Radium in 2 Fällen von Sarkom berichtet Flemming ${ }^{182}$ ). Kasuistische Beiträge zum Sarkom liefern Schridde ${ }^{43}$ ) und Hollowa ${ }^{253}$ ). Eine merkwürdige Operation machte $\mathrm{Zirm}^{579}$ ): in einem Falle, wo Enucleation verweigert wurde, entfernte er ein Sarkom aus einem Augapfel; nach 14 Monaten war scheinbar noch kein Rezidiv aufgetreten. Das Carcinom wird als metastati sches bei einem primären Rectumtumor erwähnt von Aris awa ${ }^{29}$ ), bei einem Mammakrebs von Gallemaerts ${ }^{198}$ ). - Endlich einige experimentelle Arbeiten. $\mathrm{R}$ ube $\mathrm{ns}^{\mathbf{4 7}}$ ) transplantierte von Ratten-Spindelzellensarkom teils Gewebsstückchen, teils Aufschwemmungen in Kochsalzlösung in die Vorderkammer bzw. in den Glaskörper von Ratten. Von 8 Impfungen zeigten 6 Wachstum, von 13 Injektionen in die Vorderkammer waren 5, von 7 Injektionen in den Glaskörper 2 erfolgreich. Die Impfgeschwülste wuchsen rascher als von selbst entstandene Geschwülste. Impfungen auf Kaninchenaugen waren erfolgios. Happa ging ähnlich vor bei der Übertragung von Kaninchensarkom auf Kaninchenaugen ${ }^{229 a}$ ); er injizierte Tumormaterial auBerdem in die Bindehaut und Hornhaut. Subconjunctival entwickelten sich schnell Tumoren, die sich jedoch bald zurückbildeten. In ähnlicher Weise arbeitete Hegner an Mäusen ${ }^{235}$ ). Besonders starkes Wachstum zeigte das Material, das durch mebrere Tierpassagen virulent gemacht worden war. Das Spontantumoren entnommene Material blieb hinter jenem im Wachstum weit zurück. Alle Bulbi reagierten mit starken Entzündungserscheinungen. In einer großen Versuchsreihe gelang es Hegner auch: vereinzelt Menschensarkom auf Rattenaugen zum Wachstum zu bringen. Die Proliferationsfähigkeit war jedoch in diesen Fällen eine beschränkte. Stargardt zerrieb Hühnersarkom, filtrierte eine Aufschwemmung davon und injizierte das Filtrat Hühnern in die Vorderkammer und in den Glaskörper ${ }^{484}$ ). Er erhielt einmal typisches Sarkom in Lid, Aderhaut und Ciliarkörper. Stargardt folgert, daß der Erreger des Sarkoms zu den filtrierbaren Keimen gehört. In einer allgemeinen Arbeit über die Ätiologie der Tumoren überträgt Tiesenhausen embryonale Teile ins Gewebe erwachsener Tiere, u. a. auch in Vorderkammer und Glaskörper $\left.{ }^{511}\right)$; die embryonalen Teile entwickelten sich so, wie sie es in ihrer

Zeitschrift für Krebsforsehung. 18. Bd. 
ursprünglichen Lage getan hätten. Auch sarkomähnliche Bildungen mit späterer Resorption wurden gefunden.

Zum Schluß ist es mir angenehme Pflicht, meinem hochverehrten Lehrer, Herrn Prof. Dr. Fehr, für die gütige Überlassung dieser Arbeit sowie das ihr entgegengebrachte rege Interesse meinen ergebensten Dank auszusprechen.

\section{Literaturverzeichnis.}

A bkürzungen.

Arch. f. O. G. = Archiv für Ophthalmologie (Graefes).

Arch. f. A. $=$ Archiv für Augenheilkunde.

Am. Journ. of $\mathrm{O} .=$ Amer. Journ. of Ophthalmology.

Ann. d'Oc. =- Annales d'Oculistique.

Ann. di Ott. = Annali di Ottalmologia.

Ann. of O. = Annales of Ophthalmology.

Arch. d'O. =Archives d'Ophthalmologie.

Arch. of $\mathrm{O} .=$ Archives of Ophthalmology.

Arch. di Ott. = Archivio di Ottalmologia.

Arch. de O. Hisp. A. = Archivos de Oftalmologia Hispano-Americanos.

Berl. kl. W. = Berliner klin. Wochenschrift.

Berl. Ophth. Ges. =- Berliner ophthalmologische Gesellschaft.
Brit. Journ. of $\mathrm{O} .=$ British Journal of Ophthalmology.

Centralbl. pr. A. = Centralblatt für praktisehe Augenheilkunde.

Clin. Ocul. = Clinica Oculistica.

Clin. Ophth. = Clinique Ophthalmologique.

D. M.W. $=$ DeutscheMed.Wochenschrift.

Kl. M. f. A. == Klinische Monatsblätter für Augenheilkunde.

M. M. W. = Münchner Med. Wochenschrift.

Vers.O.G. Heidelberg = Bericht derVersammlung der Ophthalmologischen Gesellschaft.

W. kl.W. = Wiener klin. Wochenschrift. Wjestn. O. = Wjestnik Oftalmologie.

Z.f. A. = Zeitschrift fürAugenheilkunde.

1) Adam, Statistisches, Klinisches und Anatomisches über das Glioma retinae. Z. f. A. 26, IV. 1911. - ${ }^{2}$ ) Ada mück, Über atypische Lidkrebsformen, speziell über primäre Carcinome der Meibomschen Drüsen. Wjestn. O. 1910, S. 986. - ${ }^{3}$ ) Addario-Ferla, Epithelioma papillare der Conjunetiva bulbi und des Limbus. Progresso Oftalmologico. 5. 1909-1910. - ${ }^{4}$ ) Addario-Ferla, Primäres Sarkom der Hornhaut bei einem 8 Monate alten Kinde. Ann. di Ott. 42. 1913. - 5) Agnesworth, Report of a case of melanotic sarcoma of the ciliary body. Ophth. Record. Okt. 1911. - $\left.{ }^{6}\right)$ Agricola, Fünfmal rezidiviertes Papillom der Bindehaut und Hornhaut, geheilt durch Mesothoriumbestrahlung. Kl. M. f. A. 1913, I, S. 650. - - 7) Akatsuka, Uther einen eigentümlichen Fall von Ciliarkörpersarkom. Kl. M. f. A. 1912, II. - ${ }^{8}$ ) Albanese, Über ein melanotisches Sarkom der Chorioidea mit Pigmentfleck auf der Iris. Arch. di Ott. 22, IT. 1916. - ${ }^{9}$ ) Albers-Schönberg, Melanosarkom am Cornealrand, dauernd geheilt durch Röntgenbestrahlung. M. M. W. 1920, S. 528. - io) Ales sandro, Histologische Beobachtungen und histogenetische Betrachtungen über einen Fall von primärem Epitheliom der Cornea. Clin. ocul. 14, S. 1669. 1914. 11) Alexander, Beiderseitiges Glioma retinae. D. M. W. 1911, S. 238 . 12) Ale xander, Bulbus mit Gliom. M. M. W. 1912, S. 116. - ${ }^{13}$ ) Alling, Ringförmiges Sarkom des Ciliarkörpers. - 14) Alling und Knapp, Demonstration von Ringsarkom des Ciliarkörpers. 47. Jahreskongre $\beta$ der amerik. Augenärzte 1911. - 15) Allport, Spindelzellensarkom der rechten Augenhöhle, mit Erhaltung des intakten Muskelapparates entfernt. Ophth. Record 1912. - ${ }^{16}$ ) Alt, 
Ein Fall von Peritheliom der Chorioidea. Révue générale d'Ophthalmologie 1910. - ${ }^{17}$ ) Alt, Ein Fall von cystischem Adenocarcinom des Lides. Am. Journ. of O. 1910. - 18) Alt, Spindelzellensarkom der Iris. Ibid. 1911. - 19) Alt, Mikroskopische Untersuchung eines Aderhautsarkoms (ron Green beschrieben). Ibid. 1912. - 20) Alt, An intraocular sarcoma in coexistence with an orbital perithelioma. Ibid. 1914. - ${ }^{21}$ ) Alt, An intraocular angiomatous spindelcell sarcoma with bone formation. Probable aplasie of the optic nerve. Ibid. 1915. - ${ }^{22}$ ) Alt, Ungewöhnliche epitheliale Geschwulst der Augapfelbindehaut, anscheinend ein unpigmentierter Naevus cysticus. Ibid. 1916. - ${ }^{23}$ ) Alter, Melanotic sarcoma of choroid. Ophthalmology 8, 440. 1912. - ${ }^{24}$ ) Amat, Marin, Melanosarkom der Ciliargegend. Arch. de O. Hisp. A. 1919, Heft 3, S. 118. - 25) Anton, Pathologisch-anatomische Beiträge zur Mißbildungslehre des Sehnerveneintrittes, zur Kasuistik der psammösen Endotheliome des Sehnerven und der Epidermoidcysten der Orbita. Inaug.-Diss. Leipzig 1915. - 26) Arganaráz, Contribucion al estudio del Pigmento en los sarcomas de las corioides. Boletin de la Sociedad de Oft. de Buenos Ayres 1915, S. 81. - 2i) Arganaráz, Zur Prognose des Sarkoms der Chorioidea. Arch. de O. Hisp. A. 1916, S. 35. - ${ }^{28}$ ) Arganaráz y Belgeri, Ein Fall von Leukosarkom der Iris. Act. y trab. d. l. congr. nac. de med. Buenos Ayres 1919. - ${ }^{29}$ ) Arisawa, Zur Kenntnis der metastatischen Tumoren im Auge. Vers. O. G. Heidelberg 1913. - ${ }^{30}$ ) Aris a wa, Über echtes Carcinom der Retina. Kl. M. f. A. 1914. - ${ }^{31}$ ) Aris awa, Metastatisches Aderhautcarcinom bei latentem Primärtumor. Kl. M. f. A. 1914. - ${ }^{32}$ ) As k, Ein Fall von Cancer prostatae mit Metastasen in beiden Augen. Hospitalstidende 1914, S. 475. ${ }^{33}$ ) Ask, Ein Fall von Iristumor. Ibid., S. 500. - ${ }^{34}$ ) Aubinea u et Civel, Considérations sur quelques tumeurs de l'orbite. Recueil d'Ophth. 1910, S. 143. $-{ }^{35}$ ) Aurant et Ge net, Tumeur mélanique de la chorioide propagée au corps ciliaire et à l'iris. Bulletin dela Soc. d'Ophth. de Lyon 1913, S. 52. - ${ }^{36}$ ) D'A y re n $\mathrm{x}$ et Sp éville, Tumeur orbitaire et glaucome chronique simple. Soc. franç. d'Ophth. 1914. - ${ }^{37}$ ) Ayres, Glioma of the retina. Am. Journ. of O. 1911, S. 106. $\left.{ }^{38}\right)$ Axenfeld, Zur Pathologie und Therapie der Lidcareinome. Tereinigung südwestdeutscher Augenärzte 1912. - ${ }^{39}$ ) Axenfeld, Doppelseitiges Glioma retinae und intraokulare Strahlentherapie. Kl. M. f. A. 1914. - ${ }^{40}$ ) Axenfeld, $\mathrm{K} n \ddot{u}$ pfer und Wiedersheim, Glioma retinae und intraokulare Strahlentherapie. Kl. M. f. A. 1915. - $\left.{ }^{41}\right) \mathrm{Bach}$, Carcinom des inneren Lidwinkels. M. M. W. 1912, S. 226. - ${ }^{42}$ ) Baer-Weidler, Rundzellensarkom der Orbita. - ${ }^{43}$ ) Bailoni, Über den Zusammenhang zwischen intraokularem Sarkom und Trauma. 44) Ballaban, Zur Erklärung der Netzhautspaltung bei intraokularem Aderhautsarkom. Arch. f. O. G. 4. 1918. - ${ }^{45}$ ) Brane, Sarcoma of ciliary body. Transillumination. Ophthalmic Record 1913, S. 198. - $\left.{ }^{46}\right)$ Baquis, Die Jequiritinbehandlung der Lidepitheliome. Ann. di Ott. 40. 19ll. - 4i) Barbezat von les Bayards, Zur Kenntnis des Carcinoma cylindromatodes der Orbitalgegend. Inaug.-Diss. Basel 1917. - ${ }^{48}$ ) Beauvie ux, Les tumeurs de la caroncule lacrymale et du rempli sémilunaire. Arch. d'O. 33, 216. 1913. - ${ }^{49}$ ) Behr, Über das unter dem klinischen Bilde der tuberkulösen Knötcheniritis verlaufende Glioma retinae. Centralbl. pr. A. 1919. - ${ }^{50}$ ) Bell, Report of a case of primary sarcoma of the iris; with remarks. Arch. of 0. 46, 505. 1917. - 51) Bell und Tonsey, Non operable tumors of the orbit and brow, treated successfully with radium. Arch. of O. 48, 531. 1919. - ${ }^{52}$ ) Bens on, Extradurale Sehnervengeschwülste. Transact. of the ophth. society of the United Kingdom. Vol. 31, Fase. III. 1911. - ${ }^{53}$ ) Bentzen, Ein Fall von Melanosarcoma chorioideae bei einem Patienten, der 7 Jahre früher an Cancer mammae operiert war. Hospitalstidende 1915, S. 276. _. $\left.{ }^{54}\right)$ Berens, Melanosarcoma of the orbit. Ophth. Record 1911, S. 79. - 
55) Berg, Präretinales Aderhautsarkom (Frühoperation der nicht abgelösten Netzhaut). Kl. M. f. A. 1914. - $\left.{ }^{56}\right)$ Berg meister, Ringsarkom des Ciliarkörpers. Arch. f. O. G. 75, 3, S. 474. 1910. - ${ }^{57}$ ) Berg meister, Melanosarkom der Conjunctiva. Ophth. Ges. in Wien. 20. II. 1910. - ${ }^{58}$ ) Bergmeister, Ein Beitrag zur Gliomfrage. Z.f. A. 24, Heft 4. 1910. - ${ }^{59}$ ) Bergmeister, Ein Fall von Angiom der Chorioidea. Arch. f. O. G. 79, 2. 1911. - ${ }^{60}$ ) Bergmeister, Über multiple Naevustumoren der Conjunctiva. Arch. f. O. G. 82, 541. 1912. 61) Bergmeister, Ruptur der Membrana Descemeti mit partieller Nekrose der Hornhaut im Gliomauge. Z. f. A. 32, 205. 1914. - ${ }^{62}$ ) Bertscher, Über zwei Fälle von primärem Lidsarkom. Inaug.-Diss. Tübingen 1910. - ${ }^{63}$ ) Betti, Epibulbäres Spindelzellensarkom. Ann. di Ott. 40. 1911. - ${ }^{64}$ ) Bialetti, Zwei neue durch das Jequirity geheilte Epitheliomfälle. Ann. di Ott. 41. 1912. 65) Bietti, Metastatisches, endotheliales Sarkom im Musculus rectus inferior. Kl. M. f. A. 1915, S. 462. _- ${ }^{66}$ ) Birch-Hirschfeld, Zur Kenntnis der Mischtumoren der Tränendrüse. Arch. f. O. G. 90, 1. 1917. - ${ }^{67}$ ) Birch-Hirschfeld, Ein bemerkenswerter Fall von Carcinom der Orbita. Arch. f. O. G. 90, 1. 1917. - $\left.{ }^{68}\right)$ Birch-Hirschfeld, Zur Kenntnis der melanotischen Geschwülste des Auges und seiner Umgebung. Z.f. A. 43, 201. 1920. - ${ }^{69}$ ) Birch.Hirschfeld und Siegfried, Zur Kenntnis der Veränderungen des Augapfels durch Druck eines Orbitaltumors. Arch. f. O. G. 90, 1. 1917. - 70) Black, Papilloma of the conjunctiva. Ophth. Record. 1912, S. 680. - ${ }^{71}$ ) Blagoweschtschensky, Ein Fall von Papillom der Hornhaut. Wjestn. O. 31, 13. 1913-1914. - ${ }^{72}$ ) Blair, Endotheliom der Tränendrüse. Transact. of the ophth. society of the United Kingdom 31, I. 1911. - ${ }^{73}$ ) Boettger, Ein Fall von Tränendrüsentumor. Inaug.Diss. Berlin 1910. - $\left.{ }^{74}\right)$ Bogats ch, Endothelioma lymphangiomatosum orbitae. Kl. M. f. A. 13, 477. 1912. - ${ }^{75}$ ) Boggi, Ein Fall von Epitheliom der Lid-Nasengegend mit Jequirity behande]t. Ann. di Ott. 40. 1911. -- ${ }^{76}$ ) Böhm, Ein ungewöhnlicher Fall von epibulbärem Carcinom. Kl. M. f. A. 1917. - i7) Böhm, Über Veränderungen des Auges durch den Druck einer orbitalen Neubildung. Kl. M. f. A. 58. 1917. - ${ }^{78}$ ) Bon nefoy, Leucosarcome en nappe de la chorioide. Société franç. d'Ophth. 1914. - $\left.{ }^{79}\right)$ Borch, Les épithéliomas du limbe sclérocornéen (étude anatomo-pathologique). Thèse de Paris 1914. - ${ }^{80}$ ) Bossalino, Widerstandsfähigkeit der Hornhaut gegenüber der Invasion einer Neubildung epithelialen Ursprunges. Ann. di Ott. 41, 507. 1912. - ${ }^{81}$ ) Botteri, Beitrag zur pathologischen Anatomie des Chorioidealsarkoms. Kl. M. f. A. 1910. 82) Boudier et Velter, Un cas de papillome de la caroncule lacrymale. Arch. d'O. 31, 45. 1912. - ${ }^{83}$ ) Boulai, Relative Gutartigkeit der oberflächlichen melanotischen Carcinome des Augapfels. Clin. Ophth. 1914. _ ${ }^{84}$ ) Boussi, Les épithéliomas de la paupière. Thèse de Paris 1914. - ${ }^{85}$ ) Braunschweig, Über Behandlung maligner Tumoren mit Röntgenstrahlen. Vereinigung der Augenärzte der Provinz Sachsen. 1913. - ${ }^{86}$ ) Brav, Sarcoma of the chorioid. Am. Journ. of O. 61, Nr. 9. 1913. - ${ }^{87}$ ) Brose, A case of adenoma of the lacrymal gland. Journ. of the Amer. med. assoc. 1910. - ${ }^{88}$ ) B urk, Die Behandlung der Hornhautepitheliome durch Röntgenstrahlen. Strahlentherapie 1. 168. 1912. - ${ }^{89}$ ) Burney, Diffuse (epibulbäre und palpebrale) Carcinose der Conjunctiva. Kl. M. f. A. 1914. - ${ }^{90}$ ) Burtzef, Pigmentierte Papillome des Lides. Petersburger ophth. Ges. 1913. - ${ }^{91}$ ) Butler, A case of sarcoma of the lacrymal sac. Arch. of O. 43, 16. 1915. - ${ }^{92}$ ) Byers und Gordon, Tumors of the optic nerve. Am. Journ. of $O$. 1913. - ${ }^{93}$ ) Calderaro, Beitrag zur Lehre des Initialglioms der Netzhaut. Clin. Ocul. 11. 1910. - ${ }^{94}$ ) Camison. Un caso de glioma de la retina. Arch. de O. Hisp. A. 1914, S. 370. - ${ }^{95}$ ) Ca m pbell, Report of four cases of orbital tumors. Arch. of O. 45, 551. 1918. —6) Capron, Multiple melanotische Naevi der Con- 
junctiva mit Übergreifen auf den Limbus. Transact. of the americ. ophth. Soc. 14, 322. 1915. - ${ }^{97}$ ) Cas ali, Drei Fälle von Glioma retinae. Ann. di Ott. 39. 1910. - ${ }^{98}$ ) Lo Cascio, Sulla costituzione del pigmento dei sarcomi melanotici della coroide - Ricerche cliniche. Clin. Ocul. 1915. - ${ }^{99}$ ) Cas olino, Pathologischanatomischer Beitrag zum epibulbären Epitheliom. Arch. di Ott. 21, 540. 1914. - ${ }^{100}$ ) Casolino, Di un linfo-sarcoma della conjunctiva bulbare. Arch. di Ott. 23. 1916. - 101) Cas par, Ein Fall von ererbtem Netzhautgliom. Centralbl. pr. A. 1911, S. 161. - 102) Castelain, Note sur la sémiologie de sarcom de la région ciliaire. Ann. d'Oc. 1918. - ${ }^{103}$ ) Castresana, Sarcoma melanica chorioideo. Arch. de O. Hisp. A. 1915, S. 379. - 104) Cavara, Contribution à l'emploi du radium dans l'épithélioma des paupières. Ann. d'Oc. 146, 256. 1911. - 105) Chail lous, Dermo-Epitheliom (Parinaud). Bulletins et mémoires de la société française d'Ophth. 28. Jahrg. 1911. - 106) Chaillous, Die Metastasen der bösartigen Geschwülste an der Basis der motorischen Nerven des Auges. Ann. d'Oc. 1912. - 107) Chance, Behandlung von Sarkomrezidiven am Limbus mit elektrischer Austrocknung. Derm. med. Journ. 1916. - 108) Charles, A positive focal tubereulin reaction in a spindlecell sarcoma, which had perforated the sclera. Arch. of $\left.0.48,536.1919 .-{ }^{109}\right) \mathrm{Charlet}$, Sehnervenatrophie und Sarkom der Orbita. Revue générale d'Ophth. 1912, Nr. 1. - 110) Chevalier, Ein Epitheliom des Oberlides. Soc. franç. d'Ophth. 1910. — ${ }^{111}$ ) Chevalier, Über einen Fall von Leukosarkom der Chorioidea. Soc. franç. d'Ophth. 1911. - ${ }^{112}$ ) Chevallerea u, Affret et Boussi, Epibulbäre Tumoren. Soc. franç. d'Ophth. 1914. — 113) Clapp, Ein Fall von Melanosarkom der Aderhaut mit negativem Durchleuchtungsresultat. Am. Journ. of O. 1917. - ${ }^{114}$ ) Cla use n, Metastatisches Carcinom der Chorioidea. Berl. Ophth. Ges. Referat: K]. M. f. A. 2, 778. 1911. - 115) Clegg, Sarkom der Augenhöhle. Ophthalmic Review 1915, S.164. - $\left.{ }^{116}\right)$ Clunet et Offret, Les tumeurs du limbe cornéen. Révue générale d'Ophth. 1913, S. 353. — 117) Coats, Lymphom und Lymphosarkom der Bindehaut. Arch. of O. 44, 3, S. 235.1915. - 118) Coats, Geschwülste, ausgehend von den Schweißdrïsen. Royal London Ophthalmic Hospital Reports 1912, S. 280. - 119) Coats, Beiträge zur lokalen Metastasenbildung intraokularer Sarkome. Royal London Ophthalmic Hospital Reports 1912, S. 284. - 120) Coats, Papilloma and sebaceous adenoma of the caruncle. Ophth. Record. 1912, S. 120. - ${ }^{121}$ ) Cohen, Primary intradural tumor of the orbital portion of the optic nerve. Arch. of $0.48,19.1919 .-{ }^{122}$ ) Collins, Heilung eines epibulbären Epithelioms mit Radiumbromid. Ophthalmic Review 1915, S. 187. - 123) Colo mbo, Uber das sog. Dermoepitheliom der Bindehaut (Parinaud). Ann. di Ott. 44. 1915. - ${ }^{124}$ ) Combaud, Cancer métastatique des parties molles de l'orbite. Thèse de Paris 1913. - 125) O'Connor, Glioma retinae et Atrophia bulbi. Arch. of O. 46, 298. 1917. - ${ }^{126}$ ) Contino, Neue Beobachtungen über die Papillome des Limbus und der Hornhaut, Arch. f. A. 68, 4. 1912. - 127) Coover, Small-spindle cell sarcoma of the ciliary body. Ophth. Record. 1912, S. 360. - 128) Cords, Carcinoma orbitae, ausgehend von der Karunkel. Z. f. A. 30, 2-3. 1913. - ${ }^{129}$ ) Cosmettatos, Rezidivierendes Epitheliom der Conjunctiva bulbi. Tod durch Metastase. Ann. d'Oc. 1918. - ${ }^{130}$ ) Cramer, Epibulbäre, farblose Geschwulst. Vereinigung der Augenärzte der Provinz Sachsen 1913. - 131) Crigler, Epibulbar sarcoma, with microscopic and macroscopic sections. Arch. of O. 64, 1. 1915. - ${ }^{132}$ ) Cunningham, Epitheliom der Hornhaut. Transact. of the Ophth. Society of the United Kingdom. 30, II. 1910. 133) Dahms, Beitrag zur Kenntnis der retrobulbären Tumoren. Inaug.-Diss. Berlin 1916. - ${ }^{134}$ ) Danis, Tumeurs de la caroncule lacrymale. 28. Bulletin de la société belge d'Ophthalmologie. 29. V. 1910. - $\left.{ }^{135}\right)$ Danis, Epitheliom des Limbus. Soc. belge d'Ophth. 1911. - ${ }^{136}$ ) Davis, Bericht über zwei Orbital- 
tumoren. Am. Journ. of O. 1, 828. 1918. - ${ }^{137}$ ) Dean, Report of a case of primary sarcoma of the cornea. Ann. of O. 22, 628. 1913-1914. - . 138) Delitala, Heilung eines Falles von Epitheliom des unteren Lides und der Nase mit Jequirity. Ann. di Ott. 50. 1911. - 139) Delmonte, Beitrag zum Studium des sog. Netzhautglioms. Ann. di Ott. 50. 1911. - 140) Delmonte, Angiosarkom und rundspindeliges melanotisches Sarkom der Iris und des Ciliarkörpers. Arch. di Ott. 20. 1913. - 141) Demaria und Arganaráz, Metastatischer Aderhautkrebs. Boletin de la Sociedad oftalmologia de Buenos Ayres 2, 2. 1915. - ${ }^{142}$ ) Der uche, Carcinoma of the caruncle with report of a case. Ophthalmologie 1915. $\left.{ }^{143}\right)$ Deutschmann, Über ein atypisches Netzhautgliom. Z. f. A. 27, 3, S. 225. 1912. - 144) Deutschmann, Über intraokularen Tumor und Strahlentherapie. Z. f. A. 33, 3 und 4, S. 286. 1915. - ${ }^{145}$ ) Dickson, Ein Fall von epibulbärem Leukosarkom. The Ophthalmoscope 1914. - 146) Dimmer, Doppelseitiges Netzhautgliom. W. kl. W. 1916, Nr. 50, S. 1603. - ${ }^{147}$ ) Dodd, A case of epithelioma of the lid. Ophth. Record. 1912, S. 290. — 148) Duclos, Epithélioma pavimenteux lobulé à globes épidermiques développé aux dépens d'une tumeur dermoide (embryone) du limbe. Ann. d'Oc. 147, 35. 1912. - 149) Duclos et Sabot, Intraokularer Tumor. Ann. d'Oc. 1911. - 150) Dunbar, Two cases of epithelioma of the eyeball and lids. Arch. of O. 48, 536. 1919. — ${ }^{151}$ ) Du puis Dutemps, Epitheliom der Orbita. Soc. de Ophth. de Paris 1911. — 152) Du vigneaud et Duclos, Scheibenförmiges Aderhautsarkom. Soc. de Ophth. de Paris 1912. - ${ }^{153}$ ) van Duyse, Leiomyome sarcomatode. Arch. d'O. 1911. 154) van Duyse, Tumeur épithéliale mixte localisée entre les glandes Jacrymales palpébrale et orbitaire. 28. Bulletin de la Soc. Belge d'Ophth. 1910. - 155) van Du yse, Myxochondrosarkom der Orbita. Arch. d'O. 1913. _ ${ }^{156}$ ) van Duyse, Carcinome pavimenteux non kératinisant adénomatode de la glande de Meibomius. Arch. d'O. 34, 355. 1914. - ${ }^{157}$ ) van Duyse, Über die epithelialen Geschwülste der Augenhöhle. Arch. d'O. 1920, S. 257. - 158) van Duyse et A ubinea u, Epitheliom der Augenhöhle. Arch. d'O. 1919, S. 393. - ${ }^{159}$ ) Ebert, Über einen Fall von Lymphosarkom mit Metastasen, rechts in der Tränendrüse, links in der Orbita. Inaug.-Diss. Heidelberg 1917. -- ${ }^{160}$ ) Eicke, Ein Peritheliom des Lides. Kl. M. f. A. 1913. - 161) Ellet, A primary intradural tumor of the optic nerve. Removal with preservation of the ball. Section of ophth. americ. med. Association 1916. - ${ }^{162}$ ) Elliot, Eine Augengeschwulst mit besonderen Erscheinungen. Ophthalmoscope 1915. - 163) Elliot und Ingram, Sechs Fälle von Geschwülsten der Tränendrüse mit anatomischem Befund. Ophthalmoscope 1914. — $\left.{ }^{164}\right)$ Els ch nig, Iristumorenfälle. Kl. M. f. A. 49, 744. 1911. _ ${ }^{165}$ ) Els ch nig, Über Operation inoperabler Lid-Orbitalcarcinome. W. M. W. 1914, Nr. 1. 166) Elschnig, Zur Kenntnis des primären Retinatumoren. Arch. f. o. G. 87, II. 1914. - 167) Els chnig, zur Kenntnis der primären Netzhautgeschwölste. W. M. W. 1913, Nr. 43. - ${ }^{168}$ ) Eymann, Kontaktcarcinom der Conjunctiva palpebralis und der Cornea. Kl. M. f. A. 2, 339. 1915. _ ${ }^{169}$ ) Fage, Sarkom der Orbita. Recueil d'Ophth. 1911, Nr. 10. - ${ }^{170}$ ) Fage, Melanosarkom der Chorioidea und Betrachtungen über die Prognose. Recueil d'Ophth. 1911, Nr. 2. 171) Fage, Primäres Irissarkom. Ann. d'Oc. 156, 375. 1919. - 172) Faucher, Intradurales Gliom des Nervus opticus mit makroskopischem und mikroskopischem Befund. The Ophthalmic Record 1910. — ${ }^{173}$ ) Fa ye, Primäres Irissarkom. Arch. of O. 1919, S. $678 . \quad-{ }^{174}$ ) Fehr, Lymphangiom der Orbita. Centralbl. pr. A. 1910, S. 209. - 175) Fehr, Das Augenspiegelbild des metastatischen Aderhautcarcinoms. Kl. M. f. A. 1918. - ${ }^{176}$ ) Fejer, Ein Fall von kontralateraler Atrophie des Sehnerven, verursacht durch Sarcoma retrobulbare. Centralbl. pr. A. 1912, S. 293. - ${ }^{177}$ ) Ferruglio, Ein Fall von Lidepitheliom, geheilt mit dem aktiven 
Prinzip des Jequiritys. Ann. di Ott. 1912, S. 115. - 178) Fila tow, Sarcoma limbi. Odessaer Ophth. Ges. 2, II. 1910. - 179) Fischer, Über die Behandlung der Lidkrebse. Section of ophth. of the Americ. med. Association 1914. — 180) Fleischer und Bertscher, Über ein papilläres Lidsarkom. Kl. M. f. A. 1911. 181) Fleming (London), Beiderseitiger Netzhautmarkschwamm mit mehrfachen Metastasen. Brit. Journ. of O. 1917. - ${ }^{182}$ ) Fle m ming, Zwei Fälle von Sarkom des Augapfels, mit Radium und Mesothoriumstrahlen behandelt. Berl. Ophth. Ges. 1913. - 183) Fliescher, Ein Fall von Glioma retinae mit Phthisis bulbi. Inaug.-Diss. Heidelberg 1913. - ${ }^{184}$ ) Franke, Metastatisches Aderhautsarkom. M. M. W. 1912, S. 838. -- 185) Franz. Hypotonia bulbi bei intraokularem Tumor. K1. M. f. A. 64, 348. 1920. - ${ }^{186}$ ) Freytag, Über das Papilloma conjunctivae. Arch. f. O. G. 90, 367. 1915. - ${ }^{187}$ ) Friedenwald, Giant cell sarcoma of the orbit. Am. Journ. of O. 1914. - ${ }^{188}$ ) Fromaget, Papillom der Caruncula lacrymalis. Ophth. Provinciale 1913. - ${ }^{189}$ ) F uchs, Über Sarkom der Aderhaut nebst Bemerkungen über die Nekrose der Uvea. Arch. f. O. G. 7r, 2, S. 304. 1910. ${ }^{190}$ ) Fuchs, Demonstration eines äußerst kleinen Sarkoms der Aderhaut. Am. Journ. of O. 1911. - 191) Fuchs, Tumor des retinalen Epithels. Ophth. Ges. in Wien 1911. - $\left.{ }^{192}\right) \mathrm{Fuchs,} \mathrm{Nachtrag} \mathrm{zur} \mathrm{Arbeit} \mathrm{über} \mathrm{Sarkom} \mathrm{der} \mathrm{Aderhaut}\left({ }^{189}\right)$. Arch. f. O. G. 81, 3. 1912. - ${ }^{193}$ ) Fuchs, Limbuscarcinom unter die Aderhaut wachsend. Kl. M. f. A. 1916. - $\left.{ }^{194}\right)$ Fuchs, Über Pigmentierung, Melanom und Sarkom der Aderhaut. Arch. f. O. G. 94, 1, S. 43. 1917. - ${ }^{195}$ ) F us ci, Recurrence of orbital sarcoma, successfully treated with radium. The Ophthalmoscope 1916. - ${ }^{196}$ ) Galezowsky, Über ein konstantes Symptom bei Sarkom des vorderen Bulbusabschnittes. Soc. d'Ophth. de Paris 1910. - ${ }^{197}$ ) Galezowsky, Leucosarcome de la chorioide. Ann. d'Oc. 147, 301. 1912. - 198) Galle maerts, Cancer métastatique de l'oeil droit. Bull. de la Soc. Belge d'Ophth. 1912, Nr. 33, S. 34. - ${ }^{199}$ ) Gallemaerts, Melanosarcome, en nappe de la paupière. Ann. d'Oc. 1919, S. 216. - ${ }^{200}$ ) Gallemaerts, Mélanosarcome de la conjunctive. Ann. d'Oc. 1919, S. 129. - ${ }^{201}$ ) Genet, Gliome de la retine. Journ. des méd. pract. de Lyon et de la Région 1913. _ _ ${ }^{202}$ ) Ge net, Metastatisches Carcinom der Orbita, das entfernt wurde durch ,Orbitotomie externe curviligne“. Révue générale d'Ophth. 1913. - ${ }^{203}$ ) Gerlach und de Klejin, Papillitis door ethmoiditis of tumor orbitae. Ned. Tijdschr. v. Geneesk. 1, 405. 1910. - 204) Gifford, A case of Leucosarcoma of the iris, treated by radium. Arch. of O. 4\%, 241. 1918. _ 205) Ginestous, Augengeschwülste. Ophth. Provinciale 1912, Nr. 12. - ${ }^{206}$ ) Ginestous und Campana, Sarcome mélanotique de l'orbite. Révue générale d'Ophth. 1912, S. 515. - ${ }^{207}$ ) Gins berg, Demonstration eines punktförmigen Aderhautsarkoms. Berl. Ophth. Ges. 1911. - ${ }^{208}$ ) Ginsberg, Gefäßtumor der Netzhaut. Berl. Ophth. Ges. 1913. - 209) Giri, Die Kontaktinfektion beim Krebs des Auges. Ophthalmoscope 1913. - ${ }^{210}$ ) Glees on, Report of a case of the retina in a child eight months old. The ophth. Record 23, 242. 1914. - ${ }^{211}$ ) Golowin, Über subvaginale Exstirpation von Sehnerventumoren. Kongreß russ. Ärzte in St. Petersburg 1910. - 212) Golowin, Demonstration eines Sarkoms der Orbita. Odessaer Ophth. Ges. 8. III. 1911. - ${ }^{213}$ ) Gouvéa, Heredität der Netzhautgliome. Ann. d'Oc. 1910. - ${ }^{214}$ ) Grandclément, Heilung eines ausgedehnten epibulbären Epithelioms der Augen durch Anwendung der X-Strahlen und des Radiums. Clin. Ophth. 1913. - 215) Greeff, Metastatisches Aderhautcarcinom. Berl. Ophth. Ges. Referat: KI. M. f. A. 1911, II, S. 778. - ${ }^{216}$ ) Green, Aderhautsarkom mit ungewöhnlichen klinischen Erscheinungen. Am. Journ. of O. 1912. - ${ }^{217}$ ) Greenwood, Sarkom der Chorioidea. Transact. of the Americ. ophth. Soc. 13. II. 1913. - $\left.{ }^{218}\right)$ Greeves, Rezidivierende Lederhautgeschwulst. Transact. of the Ophth. Soc. of the United Kingdom. 32, II. 1912. _ ${ }^{219}$ ) Griffith, Drei Fälle von Seh- 
nervengeschwulst. Transact. of the Ophth. Soc. of the United Kingdom 31, II. 1911. - $\left.{ }^{220}\right)$ Griffith, Hereditary of glioma retinae. Brit. Journ. of O. 1917. 221) Groenouw, Sarkom der Augenhöhle. Krönleinsche Operation. Vereinígung schlesisch-posenscher Augenärzte 1913. - ${ }^{222}$ ) Guglianetti, Klinischer und anatomischer Beitrag zum Studium des Netzhautglioms. Arch. di Ott. 18. 1911. _ 223) Guglianetti, Über ein rezidiviertes epibulbäres Hornhautepitheliom. Behandlung mit Röntgenstrahlen. Arch. di Ott. 20. 1913. - 224) Gutmann, Metastatisches Carcinom der Aderhaut. Berl. Ophth. Ges. 1911. — 225) Habermann, Über einen Fall von Sarkom in der Gegend der Tränendrüse. Inaug.Diss. Jena 1919. - 226) Haden, Melanosarkom der Orbita. The Ophthalmic Record 1910. - 227) Hagenbach, Papillomatöses Carcinom der Stimhant und des inneren Augenwinkels. D. M. W. 1912, S. 200. — $\left.{ }^{28}\right)$ H al be n, Mit Erhaltung des Augapfels operiertes aprikosengroßes Fibrosarkom der Augenhöhle. Berl. kl. W. 1915, Nr. 52. - 229) Hansell, Epibulbäres Sarcom. The Ophthalmic Record 14. 1915. - 229a) Happe, Transplantation von Kaninchensarkom auf $\mathrm{Ka}$ ninchenaugen. Vers. O. G. Heidelberg 1913. - ${ }^{230}$ ) Harms, Über seltene Formen intraokularer Tumorer. Vereinigung württembergischer Augenärzte 1911. - 231) Hechel, Report of a case of melanosarcoma of the orbit, treated with radium. Arch. of $0.45,465.1917$. - ${ }^{232}$ ) Heed, Ein Fall von unvermutetem, kleinen, spindelzelligen Melanosarcoma chorioideae. Ophth. Sektion des Ärztevereins von Philadelphia 1912. - ${ }^{233}$ ) Heed, Intraduraler Tumor des Opticus. Transact. of the Americ. Ophth. Soc. 14, I. 1915. -- 234) Hegner, Careinommetastase in der Chorioidea, beginnend mit akuter Iritis. Kl. M. f. A. 1911. - ${ }^{235}$ ) Heg. ner, Über experimentelle Übertragung von Tumoren auf das Auge. M. M. W. 1913, Nr. 49. - 236) Heilbrun, Ein Beitrag zur Kenntnis der Neubildungen am Limbus corneae. Arch. f. O. G. 79, 540. 1910. - ${ }^{237}$ ) Heitmann, Ein bemerkenswerter Tumor des Ciliarkörpers. Kl. M. f. A. 64, 671. 1920. - ${ }^{238}$ ) Heller, Über Melanosarkom und Melanocarcinom der Conjunctiva bulbi. Inaug.-Diss. Heidelberg 1914. - ${ }^{239}$ ) He pburn, Sarkom des Ciliarkörpers. Transact. of the Ophth. Soc. of the United Kingdom 33. 1913. - ${ }^{240}$ ) Herrenschwand, Ringsarkom des Ciliarkörpers. Kl. M. f. A. 1917. - ${ }^{241}$ ) Hertel, Ringsarkom des Uvealtractus, das den Ciliarkörper, die Iris und die Aderhaut diffus infiltrierte. Vereinigung südwestdeutscher Augenärzte 1912. - 242) Hesse, Über das Adenom der Meibomschen Drüsen. Kl. M. f. A. 48, II, S. 145. 1910. - ${ }^{243}$ ) He urtel, Contribution à l'étude des tumeurs des muscles extrinsèques de l'oeil. Thèse de Paris 1914. - 244) Hippel, Strahlentherapie bei Tumoren des Auges. Arch. f. O. G. 1918, Heft 3. - ${ }^{245}$ ) Hirs ch, Über kombinierte Röntgen-Radiumbehandlung bei Lidcarcinom. Kl. M. f. A. 1911. - 246) Hirsch, Die prognostische Bedeutung des metastatischen Aderhautcarcinoms. Prager med. Wochenschr. 1911, Nr. 49. - 247) Hirs ch, Ein Fall von Papillom der Hornhaut. Arch. f. A. 85, 201. 1919. - 248) Hirschberg, Markschwamm der Netzhaut. Berlin 1869. -- 249) Hirschberg, Ein Fall von Aderhautsarkom, 28 Jahre nach der Entfernung des Augapfels beobachtet. Centralbl. pr. A. 1919, 43. Jahrg., S. 41. ${ }^{250}$ ) van der Hoeve, Röntgenuntersuchung bei Tumoren der Orbita. Z. f. A. 38, 156. 1917. _ 251) Höfle, Zwei Fälle von Epibulbärtumoren. Inaug.-Diss. Heidelberg 1915. - ${ }^{252}$ ) Höhne, Atypische Epithelwucherung am Limbus corneae. K1. M. f. A. 52, 400. 1914. - ${ }^{253}$ ) Hollow a y, Intraocular growth, probably a melanoma. Ophth. Record 1911, S. 311. - $\left.{ }^{254}\right)$ Holmes und Greeves, Flächensarkom der Chorioidea. Ophth. Society of the United Kingdom 1914. - ${ }^{255}$ ) von Hoor, Zur Malignität der gefärbten Tumoren des Auges. Kl. M. f. A. 1913. 256) Howard, Carcinoma of orbit probably originating in the lacrymal gland. Am. Journ. of O. 3, 332. 1920. - $\left.{ }^{257}\right) \mathrm{H}$ uds o n, Die primären Sehnervengeschwülste. 
Royal London Ophthalmic Hospital Reports. 18, 317. 1912. — ${ }^{258}$ ) Jack, Neubildungen der Tränendrüse. Verhandlungen der amerik. augenärztl. Ges. 1910. ${ }^{259}$ ) J a c ks on, Chorioidealsarkom. Ophth. Record 1913, S. 201. _- 259a) J a c k s o n, Sarcoma of the orbit. Ophth. Record 1912, S. 190, _ 260) Jackson und Fir moff, Sarcoma of the chorioid with secundary changes. Arch. of O. 47. 1918. - 261) Jacqueau, Gliome oculaire bilatérale. Clin. Ophth. 1913, S. 733. 262) Jarnatowski, Lymphosarcoma carunculae lacrymalis. (Autoreferat.) Centralbl. pr. A. 1914. - ${ }^{263}$ ) Ide, Bericht eines Falles von Sarcoma orbitae. Ophth. Record 1913. - ${ }^{264}$ ) Jeruglio, Fall von Lidepitheliom durch Jequirity geheilt. Ann. di Ott. 51. 1912. _ 265) Jess op, Melanotisches Sarkom am Limbus. Transact. of the ophth. Soc. of the United Kingdom 31, I. 1911. _ 266) Igers heimer, Spindelzellensarkom des Oberlides. M. M. W. 1915, S. 477. - ${ }^{267}$ ) Igers heimer, Therapeutische Versuche bei einem doppelseitigen Aderhautcarcinom. Kl. M. f. A. 56, 558. 1916. — ${ }^{268}$ ) Inouye, Zur Kenntnis der Pathologie der Tenonitis, nebst Bemerkungen über Tenonitis bei nekrotischem Aderhautsarkom. Arch. f. O. G. 81, II. 1912. _ ${ }^{269}$ ) Is chre yt, Ein Fall von Ringsarkom des Ciliarkörpers. Arch. f. O. G. 81, II. 1912. - ${ }^{\mathbf{2 7 0}}$ ) Is chreyt, Über Aderhautgeschwülste. Arch. f. A. 77, Heft 1-3. 1913. - ${ }^{271}$ ) Is chre yt, Cber einen Fall von primärem Sarkom der Orbita mit Iridocyclitis anterior adhaesiva in dem luxierten Bulbus. Kl. M. f. A. 61, 432. 1916. — 272) Is hihara, Beiträge zur pathologischen Anatomie des metastatischen Carcinoms der Chorioidea. Kl. M. f. A. 1914. ${ }^{273}$ ) Israelit, Über primäre Sarkome der Orbita. Inaug.-Diss. Berlin 1915. 274) Judin, Ein Fall von Sarkom des Musculus rectus superior. Wjestn. O. 1911, S. 40. - 275) Juler, Schnitte durch ein Rundzellensarkom des Ciliarkörpers und der Regenbogenhaut. Transact. of the Ophth. Soc. of the Lnited Kingdom 31, II. 1911. - 276) Iw u mi, Ein Fall von intraokularem Sarkom im frühen Kindesalter. Kl. M. f. A. 1910. - ${ }^{277}$ ) Kadins k y, Melanosarkom der Chorioidea. Gesellschaft der Augenärzte in Moskau 1912. - ${ }^{278}$ ) Kadletz, Über ein Sarkom der Aderhaut ohne Abhebung der Netzhaut. Ophth. Ges. in Wien 1920. - $\left.{ }^{279}\right) \mathrm{K}$ alas chnik off, Melanosarkom der Iris und des Corpus ciliare. Petersburger Ophth. Ges. 1911. $\left.{ }^{280}\right) \mathrm{Katz}$, Zwei seltene Mischtumoren aus der Gegend der Tränendrüse. Arch. f. O. G. 74. 1910. - ${ }^{281}$ ) Ka y, Interfaszikuläres Endotheliom der Chorioidea. Transact. of the Ophth. Soc. of the United Kingdom 1910. - ${ }^{282}$ ) Keiper, Melanotisches Sarkom der Chorioidea mit Abhebung der Netzhaut. Ann. of O. 1913, S. 455. - ${ }^{283}$ ) Kirkpatrick, Double Orbital Sarcoma. Brit. Journ. of O. 1917. - ${ }^{284}$ ) de Kleijn. Über die Frage der Spontanheilung bei Glioma retinae. Arch. f. O. G. 80, Il. 1911. - ${ }^{285}$ ) de Kleijn und Gerlach, Zur Prognose der bösartigen Augengeschwülste. Ned. Tijdschr. v. Geneesk. 1910, S. 1613 und 1668. 286) Klinedinst, A probable Sarcoma of the orbit. Ophth. Record 1911, S. 303. - $\left.{ }^{287}\right) \mathrm{K}$ lo p p, Primary sarcoma of the ciliary body. Newyork med. journ. 1910. ... $\left.{ }^{288}\right)$ Kna pe, Ophthalmologische Beobachtungen. Finska Läkaresälksk. Handl. 52, II, S. 533. 1910. - ${ }^{289}$ ) K n a p p, A mixed tumor of the lacrymal gland. Amerik. Ausgabe des Arch. f. A. 41. I. 1912. - ${ }^{290}$ ) $\mathrm{Kn}$ a p p, A primary tumor of the optic nerve successfully removed, with preservation of the eyeball, by the Krönlein method. Arch. of O. 14. 1915. - ${ }^{291}$ ) K na p p, Report of carcinoma of the orbit. Arch. of O. 48, 485. 1919. - ${ }^{292}$ ) Knie per, Ein Fall von doppelseitigem Glioma retinae mit Enucleation des einen und nummehr fast 11 jähriger Atrophie des anderen Auges. Arch. f. O. G. 78, II, S. 310. 1911. - ${ }^{293}$ ) Koller, Two cases of epibulbar sarcoma. Arch. of O. 41, 327. 1912. — ${ }^{294}$ ) Ko moto, Ein Fall von epibulbärem Sarkom. Nippon Gankakai Zashi 1911. - 295) Komoto, Ein Fall von Leukosarkom der Chorioidea. Ibidem 1913. ... 296) Korschenjanz, Ein Fall von Melanosarkom der Conjunctiva bulbi, entfernt mit Erhaltung des Bulbus. Wjestn. O. 1912, 
S. 670. - ${ }^{297}$ ) Koyanagi, Über einen Fall von primärem Sehnerventumor. KI. M. f. A. 1912, S. 283. - ${ }^{298}$ ) Krafft, Ein Beitrag zur Kenntnis des Melanosarkoms der Chorioidea. Inaug.-Diss. Heidelberg 1914. - ${ }^{299}$ ) Kra uss, Papilloma of the Conjunctiva. Ophth. Record 1911, S. 81. - ${ }^{300}$ ) Krauss, Demonstration einer wegen Lidcarcinoms operierten Patientin. M. M. W. 1911, S. 2309. 301) Krauss, Über einen primären Tumor der Opticuspapille. Z. f. A. 27, 142. 1912. - ${ }^{302}$ ) Kriwo nos off und Perim off, Noch einmal zur Frage der Blepharoplastik. Wjestn. O. 1913, S. 687. — ${ }^{303}$ ) Krüdener, Orbitalsarkom. Peters. burger med. Wochenschr. 1912, S. 12. - $\left.{ }^{304}\right) \mathrm{K}$ uffler, Endotheliom der Orbita. 37. Vers. O. G. Heidelberg 1911. — 305) Lamb, Peritheliom der Augenlider. The Ophthalmoscope 1913. - 306) Lange, Zur Lehre vom Sarkom der Aderhaut mit Berücksichtigung der experimentellen Geschwulstforschung und der mo. dernen Anschauungen der Histogenese der Tumoren. Kl. M. f. A. 1913. 307) de Lapersonne, Carcinom mit Atrophie des Lides und der Orbita. Soc. d'Ophth. de Paris 1910. $-{ }^{308}$ ) de La personne, Mischgeschwulst der Tränendrüse. Arch. d'O. 1912, Nr. 7. - ${ }^{309}$ ) Lattorf, Fall von primärem Melanosarkom der Iris. Berl. Ophth. Ges. 1911. - ${ }^{310}$ ) Laven, Beitrag zur Kenntnis der primären Irissarkome. Kl. M. f. A. 1913. - 311) Lawford und Greeves, Two cases of sarcoma of chorioid. Ophth. Review 1915, S. 97. _ 312) Laws on, Metastatischer Scirrhus der Augenhöhle. Transact. of the Ophth. Soc. of the United Kingdom 30, I. 1910. - ${ }^{313}$ ) Le ber, Beiträge zur Kenntnis der Struktur des Netzhaut. glioms. Arch. f. O. G. 28, II, S. 381. 1911. - 314) Lecène, Un cas de Myélocytome de l'orbite. Ann. d'Oc. 1919, S. 249. - ${ }^{315}$ ) Lediard, Melanotisches Aderhautsarkom mit Leber- und Darmmetastasen. Transact. of the Ophth. Soc. of the United Kingdom 32, III. 1912. - ${ }^{316}$ ) Lee $n$ heer, An orbital endothelioma. Ophth. Record 25, 747. 1916. - ${ }^{317}$ ) Le m berg, Zur Statistik des Uvealsarkoms 1919. - ${ }^{318}$ ) Le plat, Metastatisches Carcinom des Auges. Ann. d'Oc. 1911. ${ }^{319}$ ) Libby, Corneal papillary growth. Ophth. Record 1910, S. 303. - ${ }^{320}$ ) Lind, Über Geschwülste der Limbus corneae. Inaug.-Diss. Berlin 1915. _ 321 ) Lindahl, Über Durchleuchtungsmethoden zum Nachweis von Chorioidealtumoren. Kl. M. f. A. 45. 11. 1920. - 322) Lindenfeld, Über "Spontanheilung" von Glioma retinae. Arch. f. O. G. 86, I. 1913. - ${ }^{323}$ ) Linden me yer, Primärer Sehnerventumor. Herbstversammlung der Vereinigung hessischer und hess.-nassauischer Augenärzte 1913. - 324) Lindenmeyer, Einwirkung von Erysipel auf ein Lidcancroid. K1. M. f. A. 52, I, S. 143. 1913. _ - ${ }^{325}$ ) Lindgren, Drei Fälle von Orbitaltumoren. Hospitalstidende 1912, S. 167. — ${ }^{326}$ ) Lind ner, Gleichzeitiges Vorkommen von Carcinom und Tuberkulose. Ophth. Ges. in Wien 1914. 327) Lodberg, Ein Fall von kavernösem Melanosarkom in der Chorioidea am Papillenrande mit Retinadurchbruch. Hospitalstidende 1912, Nr. 40. - ${ }^{328}$ ) Lodberg, Demonstration von Präparaten und Photographien eines Falles von Hydroophthalmus und Glioma retinae mit Orbitalrezidiv. Hospitalstidende 1913, S. 245. - ${ }^{329}$ ) Lohfeldt, Über einen Fall von Melanosarkom, bei dem als erstes Symptom eine Scleritis eintrat. Inaug.-Diss. Jena 1913. - ${ }^{330}$ ) Löhlein, Zur Frage der primären Sehnervengeschwülste. Arch. f. O. G. 78, II. 1910. - 331) Lowzow, Ein Fall von beiderseitigem Gliom der Retina. Wjestn. O. 1913, S. 773. 332) Luedde, Simple and multiple papillomata of the conjunctiva. Am. Journ. of O. 31, 65. 1914. - ${ }^{333}$ ) Luedde, Melanosarkom des Ciliarkörpers. Am. Journ. of O. 1915, S. 168. - ${ }^{334}$ ) Maggi, Beitrag zum Studium der epithelialen Neubildungen am Limbus. Ann. di Ott. 42. 1913. - ${ }^{335}$ ) Maghi, A case of bilateral glioma of the retina in a girl twenty years of age, in which the second eye was excised after an interval of nearly eighteen years. Brit. Journ. of O. 1919. -336) Mais ch, Über zwei Fälle von Orbitaltumoren (Angiofibrosarkom, kavernöses 
Angiom), die mittels der Krönleinschen Operation entfernt wurden. Inaug.-Diss. Heidelberg 1915. - ${ }^{337}$ ) Makay, Bemerkung über einen Fall von Endotheliom der Aderhaut, das am Sehnerveneintritt gelegen ist. Transact. of the Ophth. Soc. of the United Kingdom 30, I. 1910. - ${ }^{338}$ ) Ma noles c u, Epithéliome de la cornée. Révue générale d'Ophth. 1912, S. 499. - - ${ }^{339}$ ) Marongi u, Sopra un caso di nevocarcinoma melanico primitivo della palpebra inferiore con speciale reporto sull'origine epitheliale della cellula nevica. Arch. di Ott. 26. 1919. - ${ }^{340}$ ) Marquardt, Über Fibrosarkom der Orbita. Inaug.-Diss. Leipzig 1913. - 311) Mär tens, Primärer epithelialer Tumor des Augeninneren. Vereinigung niedersächsischer Augenärzte 1913. - - ${ }^{342}$ ) Maruo, Über einen Fall von Muskelsarkom, veranlaßt durch ein Trauma. Kl. M. f. A. 68. 1910. - ${ }^{343}$ ) Mattice, Report of the successful treatment of a corneal tumor with radium, with remarks on radium in ophthalmology. Arch. of O. 43, Nr. 3, S. 237. 1914. - ${ }^{344}$ ) Ma urizi, Eigentümliche Form von Lidkrebs. La Pratica oculistica. 10. Jahrg. 1912. - ${ }^{345}$ ) Max, Irisatrophie und epibulbäres Carcinom bei Xeroderma pigmentosum. Kl. M. f. A. 1912. - 346) Maxson, Drei Fälle von Sarkom des Auges. Verhandlungen der amerikanischen augenärztlichen Gesellschaft. 48. Jahreskongreß 1912. 347) Mayou, Angeborenes Sarkom der Augenhöhle. Transact. of the Ophth. Soc. of the United Kingdom 30, I. 1910. - ${ }^{348}$ ) del Mazo, Epithelioma del parpado inferior y de la nariz tratado y curado por el radio. Arch. de O. Hisp. A. 11. Heft 9, S. 505. 1911. - ${ }^{349}$ ) Mees man n, Metastatisches Aderhautcarcinom. Berl. Ophth. Ges. 1920. - ${ }^{350}$ ) Meller, Intraokulares Sarkom und sympathisierende Entzündung. Arch. f. O. G. 22, I. 1911. - $\left.{ }^{351}\right)$ Meller, Ửber eine epitheliale Geschwulst des Ciliarkörpers. Ibidem 85, II. 1913. - ${ }^{352}$ ) Meller, Über Rückbildung von Netzhautgliom. Centralbl. pr. A. 1915, S. 101. ${ }^{353}$ ) Meller, Kleines Hornhautsarkom in einem nach perforierender Verletzung atrophisch gewesenen Auge. Centralbl. pr. A. 1916, S. 108. - 354) Menacho, Epithelioma pavimentosa de la cornea. Arch. de O. Hisp. A. 1915, S. 352. 355) Mende, Ein Fall von retrobulbärem Tumor. Petersburger med. Zeitschr. 1913, S. 252. - ${ }^{356}$ ) Mendez, Zur Kenntnis der Mischgeschwülste der Tränendrüse. Kl. M. f. A. 1910. - ${ }^{357}$ ) Mentberger, Beitrag zur Kenntnis des Melanosarkoms der Aderhaut. Inaug.-Diss. Heidelberg 1911. - ${ }^{358}$ ) Migliorino, Epibulbäres Epitheliom in einem Falle von Xeroderma pigmentosum. Ann. di Ott. 42, 675. 1913. - ${ }^{359}$ ) Mi yashita, Über Tenonitis bei beginnendem Aderhautsarkom. Kl. M. f. A. 1911, - ${ }^{360}$ ) Mona uni, Contributo all'istologia dei gliomi della retina. Arch. di Ott. 1918. - ${ }^{361}$ ) Montaño, Los casos de melanosarcoma de los parpados. Exstirpacion completa de los neoplasmas. Curación. Annales de Oftalmologia 15, Heft 11, S. 425. 1913. - ${ }^{362}$ ) Montinho, Cancroide de la conjunctive. Exstirpation. Guérison. Bulletins et Mémoires de la société française d'Ophthalmologie 1910. $-{ }^{\mathbf{3 6 3}}$ ) Moore, Four cases of melanoma of the choroid, with a pathological examination in one case; and one case of unusual chronicity, after dissemination of a melanotic sarcoma, had occured. London Ophth. Hosp. Reports 19, III. 1914. - ${ }^{364}$ ) Morax, Myélocytome orbitaire et cranien. Ann. d'Oc. 1919, S. 256. - ${ }^{365}$ ) Müller, Ein Fall von Cylindroendotheliom der Bindehaut. Ungarische Ophth. Gesellschaft, 7. Versammlung 1911. _ ${ }^{366}$ ) MulockHouwer, Demonstration eines Falles von nekrotischem Sarkom der Chorioidea. Ned. Tijdschr. v. Geneesk. 1918, S. 1663. _ 367) Murray, A case of sarcoma of the optic disk. Ophthalmology 1910. - ${ }^{368}$ ) Napp, Beitrag zum Verhalten der Netzhaut im Bereiche von Aderhauttumoren. Berl. kl. W. 47. Jahrg. 1910, Nr. 24. - ${ }^{369}$ ) z ur Nedden, Netzhautgesehwulst bei einem 17 jährigen. Versammlung rheinisch-westfälischer Augenärzte 1913. - 370) Neeper, Carcinoma, apparently primary, arising from the ciliary processes. Ann. of O. 24. 1915. - 
371) Nelson, Rarity of sarcoma of sclera. Report of a case with removal and no-recurrence. Journ. of O. 90, Nr. 23. 1915. - ${ }^{372}$ ) Nettleship, A case of sarcoma of choroid. Ophth. Record 1912, S. 383 und 684. - ${ }^{373}$ ) Neuburger, Fall von Melanosarcoma chorioideae. M. M. W. 1911, S. 1894. - 3r4) New and Benedict, Radium in the treatment of diseases of the eye and adnexa. Am. Journ. of O. 1920, III, S. 244. - ${ }^{375}$ ) Nobile, Zwei Fälle von Hautepitheliom des Lides und der Nase, geheilt mit dem aktiven Prinzip des Jequirity, Methode Rampoldi. Ann. di Ott. 39, 685. 1910. - ${ }^{376}$ ) Noyes, Two cases of cancerous tumor of the choroid. Transact. of the americ. Ophthalm. Soc. 1910. 32. annual meeting. - 377) Obarrio, Ein Cylindrom der Augenhöhle. Ophthalmoscope 1913. - 378) Offret, Naevo-Carcinome du limbe scléro-cornéen. Ann. d'Oc. 147, 303. 1912. - ${ }^{379}$ ) Ohnacker, Zur Kasuistik der Netzhautgliome. Wien. klin. Rund. schau 1910, Nr. 20-24. - ${ }^{380}$ ) Oloff, Über primäre Tumoren und tumorähnliche Bildungen an der Papilla nervi optici. Kl. I. f. A. 1915, II, S. 313. ${ }^{381}$ ) Ormond, Ein Fall von Tränendrüsengeschwulst. Transact. of the Ophth, Soc. of the . Enited Kingdom 30. II. 1910. - 382) Paderstein, Demonstration einer Zahl von Gliomen und Pseudogliomen. Berl. Ophth. Ges. 14. VII. 1910. $\left.{ }^{383}\right)$ Pálich-Szántó, Über verschiedene Formen des Lidkrebses. Arch. f. A. 89, I. 1915. - 384) Pálich-Szántó, ¿̉ber das Auftreten einer Sehnervenentzündung bei Chorioidealsarkomen. Arch. f. A. 85, III, IV. 1919. - ${ }^{385}$ ) Palmieri, Über primäres Hornhautsarkom. Ann. di Ott. 39. 1910. - $\left.{ }^{386}\right)$ Pas cheff, Untersuchungen über die Tumoren der Glandula lacrymalis. Kl. M. f. A. 1918. 387) Pa setti, Papilloma della conjunctiva bulbare. Ann. di Ott. 41, 602. 1912. - $\left.{ }^{388}\right)$ Pas etti, Epitheliom des Tränensackes. Ann. di Ott. 42. 1913. — $\left.{ }^{389}\right)$ Pe p p müller, Carcinom des Enterlides. Berl. kl. W. 1913, S. 800. - ${ }^{390}$ ) Pereyra, Beitrag zum Studium der epibulbären Melanosarkome. Ann. di Ott. 42. 1913. - ${ }^{391}$ ) Pereyra, Del sarcoma palpebrale primario. Arch. di Ott. 23. 1916. 392) Perrod, Beitrag zur Onkologie des Auges. Ann. di Ott. 40. 1911. -${ }^{393}$ ) Perrod, Beiträge zur Onkologie des Auges. Ibid. 42. 1913. - ${ }^{394}$ ) Peschel, Ein neuer histologischer Befund bei Glioma retinae. D. M. W. 1910, S. 1279. ${ }^{395}$ ) Peter, Tuberculosis of the conjunctiva and sclera following removal of a pigmented papilloma of conjunctiva. Ophth. Record 1912, S. 120. - ${ }^{396}$ ) Piccaluga, C̈ber das Papillom der Cornea. Kl. M. f. A. 1913, II, S. 73. — ${ }^{397}$ ) Pindikowski, Über das Oberflächenwachstum intraokularer Sarkome, zugleich ein Beitrag zur Kasuistik der Ringsarkome. Kl. M. f. A. 1914. - ${ }^{398}$ ) Platt, Ein Fall von Nebennierensarkom mit Metastacen in den Augenhöhlen. Ophthalmoscope 1911. - ${ }^{399}$ ) Pokrowsky, Ein Fall von Sarkom der Bindehaut, von einem Naevus pigmentosus ausgehend. Ges. der Augenärzte in Moskau 1912. -${ }^{400}$ ) Pokrowsky, Angiosarkom der Lidhaut. Ibid. 1912. — 401) Pokrowsky, Lidcarcinom, von den Meibomschen Drüsen ausgehend. Ibid. 1913. - ${ }^{402}$ ) Pokrowsky, Basalzellenkrebs des Lides. Ibid. 1913. - 403) Pokrowsky, Zur Lehre von den Lidgeschwülsten. Wjestn. O. 31, 215. 1914. - ${ }^{404}$ ) Poleff, Über Papillome der Hornhaut. Inaug.-Diss. Würzburg 1910. - ${ }^{405}$ ) Pollack, Gliom des Opticus. Berl. Ophth. Ges. 1920. - ${ }^{406}$ ) Pons Marqués, Sarcoma melánico de la conjunctiva. Arch. de O. Hisp. A. 1911, II, S. 145. - 407) Pons Marqués und Menacho, Melanosarkom der Chorioidea. Enucleation, Heilung. Ibid. 14, Heft 4, S. 177. 1914. - $\left.{ }^{408}\right)$ Pooley, Giant cell sarcoma of the upper lid. Proceedings of the Royal Society of Med. Sect. of Ophth. 6, 94. 1913. - ${ }^{409}$ ) Posey, Rundzellensarkom der Sehnervenscheide. Ophth. Record 1911. - 410) Posey, Klein-Rundzellen-Myosarkom der Augenhöhle mit Beteiligung des Augapfels. Ophth. Record 1912. — ${ }^{411}$ ) Pose y, Rodent ulcer of the orbit. Ibid. 1912, S. 298. — 412) Posey, Intraocular neoplasm. Ibid. 1912, S. 682. - ${ }^{413}$ ) Pose y, Prop- 
tosis of the right eye probably in consequence of an orbital tumor. Ibid. 1912, S. 675. - 414) Poulard, Epitheliom des Lides. Arch. d'O. 1910. — 415) Profeta, Epitheliom der Hornhaut. Clin. Ocul. 12. 1911. - ${ }^{416}$ ) Purt scher, Zur Kenntnis des Markschwammes der Netzhaut und seiner spontanen Rückbildung. Centralb]. pr. A. 1915, S. 193. - 417) P u s cari u, Leukosarkom ausgehend vom Ciliarkörper. Arch. d'O. 1910. - ${ }^{418}$ ) Quakenboss, Nebennierentumor mit Metastase in der Orbita. Ann. of O. 1911. - ${ }^{419}$ ) Rados, Regressive Veränderungen im Netzhautgliom. Ophth. Ges. Heidelberg 1918. - 420) Rams a y, Rundzellensarkom der linken Augenhöhle. Ophthalmoscope 1914. - 421) Raubitschek, Über Iristumoren. Kl. M. f. A. 1914, I, S. 683. - ${ }^{422}$ ) Rauch, Fall von Radiotherapie bei einem Lidcarcinom. W. kl. W. 1913, S. 1679. - ${ }^{423}$ ) Redicker, Über sekundïre Entzündung beim Gliom der Netzhaut. Inaug.-Diss. Freiburg 1913. +24) Reeder und Darling, Bericht über einen Fall von Gliom der Retina bei cinem zwei Jahre alten Jamaikaner Kinde. Ophth. Record 1914. - ${ }^{425}$ ) Reiche, Netastatische Melanosarkomknoten in der Leber bei Sarcoma chorioideae. D. M. W. 1917, S. 990. - 426) Reis, ¿̈ber diffuse Papillomatose der Cornea. Z. f. A. 24, 129. 1910. - ${ }^{427}$ ) Re is, Flächensarkom der Aderhaut. 36. Vers. O. G. Heidelberg 1910. - $\left.{ }^{428}\right)$ Reis, C̈ber Ringsarkom des Ciliarkörpers. Z. f. A. 28, Heft 5. 1912. - ${ }^{429}$ ) Reis, Kann die Abstammung des Netzhautglioms rom Pigmentepithel der Netzhaut als erwiesen gelten? Z. f. A. 33, Heft 3/4. 1915. $-{ }^{430}$ ) Re melé, Über traumatische Orbitalsarkome. Inaug.-Diss. Leipzig 1911. - 431) Rietz, Vom Gliom im Sehnerven. Hygiea (Schwed.) 1918, S. 344. --. ${ }^{432}$ ) Ring, Netzhautablösung wahrscheinlich nach Sarkom der Chorioidea. Ophth. Sektion des Ärztevereins von Philadelphia 1912. - ${ }^{433}$ ) Ring, Aderhautsarkom. The Ophthalmologie 1914. - ${ }^{434}$ ) Risley, Adenosarcoma of the border of the eyelid. Ophth. Record 1911, S. 79. - ${ }^{435}$ ) Risley, A case of epithelioma of the inner angle of the orbit. Tbid. 1912. S. 79. - ${ }^{436}$ ) Ris ley, Leucosarcoma of the chorioid. Ibid. 1912, S. 261. - ${ }^{437}$ ) Rolandi, Melanom der Plica semilunaris nit drusigen Einsehlïssen. Arch. di Ott. 1914, J, S. 127. - ${ }^{438}$ ) Roll, Sarcoma of the choroid. Ophth. Review 1910, S. 89. - ${ }^{439}$ ) Rollet, Prognose der primären Carcinome der Orbita. Arch. d'O. 1910. - $\left.{ }^{40}\right)$ Rollet, Six ablations de cancers orbitaires avec conservation de l'oeil, résultats ćloignés. Soc. française d'Ophth. 1914. 4:1) Rollet et Genet, Epithélioma cutanéo-nuqueux des paupières. Lyon. méd. 1913, Nr. 29. - 442) Rollet et Genet, Cancer métastatique de l'orbite. Rérue générale d'Ophth. 1913, S. 517. - ${ }^{443}$ ) Römer, Mélanosarcome pédiculé du culde-sac conjunctival. Ann. d'Oc. 15\%, 166. 1920. - ${ }^{444}$ ) Roper, Melanotisches Bindehautsarkom. Transact. of the Ophth. Soc. of the Cnited Kingdom 32. II. 1912. - - 145) Rosen berg, Zur Chirurgie und pathologischen Anatomie der Endotheliome des Auges. Russk. Wratsch 1910, S. 1051. - 446) Rosenhauch, Utber die Papillome des Limbus. Kl. M. f. A. 1912. - ${ }^{447}$ ) $\mathrm{R}$ ube $\mathrm{n}$, Über intraokulare Transplantation von Rattensarkom. Arch. f. O. G. 81, II. 1912, - ${ }^{448}$ ) R u m. baur, Klinik und Anatomie einiger seltener Tumoren des Auges und der Orbita. Kl. M. f. A. 64, 790. 1920. - ${ }^{449}$ ) R u mszewicz, Ein Beitrag zur Pathologie der Aderhautsarkome. Postẹp Okulistniczny 1912, S. 101 und 150̃. - ${ }^{4}$ ) Rutschmann, Ein Fall von einem Epithelioma fibrosum conjunctivae bulbi (Papillom) mit Cystenbildung. Inaug.-Diss. Kiel 1911. _-451) Sattler (Cincinnati), Radiumbehandlung bei Orbitalmetastasen nach Sarkom im Augapfel. Transact. of the Americ. Ophth. Soc. 50. annual meeting 1914. - ${ }^{452}$ ) Schäfler, Beitrag zur Kenntnis der Papillome der Cornea. Kl. M. f. A. 1914. - ${ }^{453}$ ) Scheerer, Ein Beitrag zur Kenntnis der Geschwülste der Meibomschen Drüsen. Kl. M. f. A. 1914. - ${ }^{454}$ ) Schieck, Das Peritheliom der Netzhautzentralgefäße, ein bislang unbekanntes Krankheitsbild. Arch. f. O. G. 81, 328. 1912. - 455) Schieck, 
Sarkom des Uvealtractus. Z. f. A. 28, 289. 1912. - ${ }^{456}$ ) Schimanowsky, Frische Resultate von Lidkrebsbehandlung mit Radiofor. Wjestn. O. 1911, S. 696. 457) Schiller, Über Sarkome der Augenlider. Z. f. A. 42, 302. 1919. ${ }^{458}$ ) Schlindwein, A case of probably malignant disease of the lacrymal duct. Ophth. Record. 1912, S. 207. - ${ }^{459}$ ) Schmiedt, Beitrag zur Kenntnis der metastatischen Orbitaltumoren. Inaug.-Diss. Leipzig 1910. - ${ }^{\mathbf{4} 60}$ ) Schneider, Melanosarcoma chorioideae. M. M. W. 1913, S. 728. - ${ }^{461)}$ Schönberg, A case of bilateral glioma of the retina apparently arrested in the non enucleated eye by radium treatment. Arch. of 0. 48, 531. 1919. _ ${ }^{462}$ ) Schre yer, Zwei Fälle von Melanosarkom an den Augenlidern. Inaug.-Diss. Erlangen 1912. - ${ }^{463}$ ) Schridde, Melanocarcinom des Auges mit Metastasen. Med. Klin. 1914. -.. ${ }^{464}$ ) de Schweinitz, Sarkom der Orbita. Am. Journ. of O. 1911. - $\left.{ }^{455}\right)$ de Schweinitz, Über Neubildungen und Pseudotumoren in der Augenhöhle. Verhandlungen der amerik. augenärztl. Ges., 47. Jahreskongreß 1911. - ${ }^{466}$ ) de Schweinitz, Epibulbar papilloma apparently originating from an injury. Ophth. Record 1911, S. 85. 467) de Schweinitz, Primärer intraduraler Tumor des Sehnerven. Ges. der Ärte von Philadelphia (ophth. Sektion) 1912. - ${ }^{468}$ ) de Schweinitz, Psammosarkom der Orbita. Verhandlung der amerik, augenärztl. Ges. 50. Jahreskongreß 1914. - ${ }^{469}$ ) de Schweinitz, Beitrag zu den Tumoren der Lider und der Orbita. Ibid. 14, 341. 1915. - ${ }^{470}$ ) de Schweinitz und Maxwell, Ein Fall von Sarcoma orbitae, der in den frühen Stadien einen Kropfexophthalmus vortäuschte. Ges. der Ärzte von Philadelphia 1910. - 471) de Schweinitz und Shumway, Epibulbäres Carcinom mit histologischer Untersuchung. Verhandlungen der amerik. augenärztl. Ges. 49. Jahreskongre $B$ 1913. - - ${ }^{472}$ ) Schwenk, A case of recurrent sarcoma of the limbus of the cornea. Ophth. Record 1910, S. 243. $\left.{ }^{473}\right)$ Sedwick, Sarcoma of the choroid. Ophth. Record 1912, S. 32. - 474) Segi, Über einen Fall von Myxosarkom des Sehnerven. Kl. M. f. A. 1913. - ${ }^{475}$ ) Selenkows ky, Zur Diagnose der Chorioidealsarkome. Russk. Wratsch 1913, S. 504. - 476) Shumway, Metastatic carcinoma of the orbit. Arch. f. A. 66, 205. 1910. - ${ }^{47}$ ) Sidler-H uguenin, Ein Endotheliom am Sehnervenkopf. Arch. f. 0 . $G$. 101, Heft 2/3. 1920. - ${ }^{478}$ ) Siegrist, Seltene Art der Ausbreitung von Gliomen der Netzhaut auf den zweiten Sehapparat. 39. Vers. O. G. Heidelberg 1913. 4i9) Siegrist, Demonstration von Tumorbildung in der Maculagegend eines $3^{1 / 2}$ jährigen Knaben. Ophth. Ges. in Heidelberg 1913. - ${ }^{480}$ ) Smirnow, Carcinom des Oberlides. Ges, der Augenärzte in Moskau 1910. - 481) Snegirew Sarkom des Tränensackes. Wjstn. O. 1910, S. 680. _- ${ }^{482}$ ) Stålberg, Ein Fall von extrabulbärem Sarkom nebst Lveitis in einem Auge und sympathischer(?) Ophthalmie im anderen. Hygiea (Schwed.) 1910, S. $768 .+{ }^{483}$ ) Stargardt, Die Röntgenbehandlung der Lidepitheliome. Strahlentlerapie und Zentralorgan für Lupusbehandlung 1913, S. 156. - ${ }^{484}$ ) Stargardt, Über einen durch filtrierbaren Virus erzeugten intraokularen Tumor (Spindelzellensarkom). Z. f. A. 33, 256. 1915. - 485) Stark, Über einen Fall von Melanosarkom der Chorioidea. Inaug.Diss. Marburg 1913. - 486) Steichele, Über das metastatische Aderhautcarcinom. Arch. f. A. 84, Heft 3 und 4. 1919. -- 487) Steiner, Pigmentflecke und Pigmentgeschwülste bei verschiedenen Rassen. Kl. M. f. A. 1913, II, S. 534. - ${ }^{488}$ ) Ste inohrt, Zur Kenntnis der epithelialen Geschwïlste der Cornea. Kl. M. f. A. 1915, II. S. 325. - - 489) Stengele, Zur Kasuistik des Ciliarkörpersarkoms. Inaug.-Diss. Heidelberg 1915. - ${ }^{490}$ ) Ste phe ns on, Primäres melanotisches Sarkom der Regenbogenhaut. Ophthalmoscope 1911. - ${ }^{491}$ ) Stephenson, Metastatisches Sarkom, von der Iris ausgehend. Referat: Centralbl. pr. A. 1913, S. 25. _. 49?) Ste phenson, Irrtümer in der Diagnose des Netzhautmarkschwammes. Ophthalmoscope 1916. - ${ }^{43}$ ) Stieren, Bericht über drei Fälle von Glioma retinae. Ophth. Record 
30. 1910. - 494) Stock, Myelom im Inneren des Auges. Kl. M. f. A. 1918. 495) Stoewer, Maligner Naevus der Carunkel. Kl. M. f. A. 1912, S. 233. 496) Stoll, Double Glioma of retina. Am. Journ. of O. 1911, S. 113. - ${ }^{497}$ ) Sulzer et Rochon-Duvigneaud, Sehnervengeschwulst. Société d'Ophth. de Paris 1913. - ${ }^{498}$ ) Sweet, Orbitaltumor mit Ausbreitung auf Stirn- und Schläfengegend. Am. Journ. of O. 1918, I, S. 830. - ${ }^{499}$ ) von Szily, Über die Entstehung des melanotischen Pigments im Auge der Wirbeltierembryonen und in Chorioidealsarkomen. Bonn, Cohen 1911. - ${ }^{500}$ ) von Szily, Experimentelle Tumoren bei Embryonen und ihre Bedeutung für die Gliomgenese. 38. Vers. O. G. Heidelberg 1912. - 501) Tamascheff, Ein Fall von pigmentiertem Lidsarkom. Russk. Wratsch 1913, Nr. 15, S. 504. - ${ }^{502}$ ) Teillais, Melanosarkom der Aderhaut. Ann. d'Oc. 1910. - ${ }^{503}$ ) Teissier et Onfray, Maculare Veränderungen im Frühstadium des Ciliarkörpersarkoms. Soc. d'Ophth. de Paris 1910. - 504) Teitz, Über Sarkome der Augenlider. Inaug.-Diss. Würzburg 1915. — ${ }^{505}$ ) Terrien, Elephantiastisches Sarkom des Oberlides. Arch. d'O. 1910. - ${ }^{505 a}$ ) Terrien, Das in die Orbita eingekapselte Sarkom und seine Exstirpation mit Erhaltung des Auges durch Schnitt am Orbitalrand. Arch. d'O. 1913. — ${ }^{506}$ ) Teuli ères, Angio-Leukosarkom der Aderhaut. Arch. d'O. 1913. - ${ }^{507}$ ) Thom pson, Zweites Orbitalendotheliom, 11 Jahre nach Entstehung des ersten. Ophth. Society of the United Kingdom 1911. _ ${ }^{508}$ ) Thorington, Leukosarkom der Iris, durch Iridektomie entfernt. Verhandlungen des 46. Jahreskongresses der amerik. augenärztl. Ges. 1910. - $\left.{ }^{509}\right)$ Thu $\mathrm{mm}$, Beitrag zur Anatomie der primären Opticustumoren. Inaug.-Diss. Tübingen 1910. _ ${ }^{510}$ ) Tis chner, Über Röntgentherapie bei Lidcarcinom. Kl. M. f. A. 1911. — 511) Tiesenhausen, Zur Ätiologie der Tumoren. Inaug.-Diss. Odessa 1910. - 512) Tolstouchow, Ein Fall von primärem Carcinom der Meibomschen Drüsen unter dem Bilde eines Papilloms. Wjestn. O. 1913, S. 498. - ${ }^{513}$ ) Toulant, Un cas de carcinome métastatique de l'iris. Arch. d'O. 1916, S. 1. - ${ }^{514}$ ) Trantas, Veränderungen des Glaskörpers bei Gliom der Netzhaut. Ibid. 1913. - ${ }^{515}$ ) Trapezontzeff, Sur un cas de mélano-sarcome de la conjonctive palpébrale. Arch. d'O, 1912, S. 429. 516) Traquair, Hereditary glioma of the retina. Brit. journ. of O. 1919. 517) Turner, Sarcoma of choroid. Ophth. Record 1912, S. 380. - 518) Ullmann, Ein Fall von metastatisehem Carcinom der Chorioidea. Inaug.-Diss. Heidelberg 1913. - i19) Uhthoff, Beitrag zur Bestrahlungstherapie bei doppelseitigem Glioma retinae mit anatomischer Untersuchung des einen bestrahlten Auges. Kl. M. f. A. 62, 6. 1919. - ${ }^{520}$ ) Valentine, Ein Fall von Leukosarkom der Aderhaut und Lippenepitheliom bei derselben Kranken. Brit. Journ. of O. 1917. - $\left.{ }^{521}\right)$ Valli, Papillomi del limbus con invasione della cornea. Ann. di Ott. 54. 1915. - ${ }^{522}$ ) Vasquez-Barrière, Bemerkenswerter Fall von Melanosarkom der Papille. Kl. M. f. A. 1911. - ${ }^{523}$ ) Veasey, Report of a case of epil ulbar sarcoma. Ophthalmology 1910. — ${ }^{524}$ ) Veasey, Cnusually large primary epithelioma of the ocular conjunctiva. Am. Journ. of O. 1920, III, S. 113. 525) Velhage n, Sarkom des Corpus ciliare. M. M. W. 1910, S. 1092. — ${ }^{526}$ ) Velhagen, Eine gliomähnliche Geschwulst (Neuroepithelioma gliomatosum syringomyeloides) des Corpus ciliare. Kl. M. f. A. 62, 571. 1919. — 527) Velhagen, Über den Befund von zwei Chorioidealsarkomen in einem Augapfel. Kl. M. f. A. 64, 252. 1920. - ${ }^{528}$ ) Verhöff, An unusual case of epibulbar sarcoma. Arch. of O. 41, II, S. 104. 1912. - ${ }^{\overline{2} 2 \%)}$ Viterbi, Geschwülste des Augapfels. Cnione tipografica Torino 1913. - ${ }^{530}$ ) Vossius, Abgekapseltes Sarkom der Orbita. Herbstversammlung hess. und hess.-nassauer Augenärzte 1913. - ${ }^{531}$ ) Wagen mann. Über Frühstadium von Aderhautsarkom. Kl. M. f. A. 51, I, S. 92.1912 . 532) Wagen mann, Glioma retinae mit temporärer Phthisis bulbi. Ibid. S. 76. - 
${ }^{533}$ ) Wainstein, Leukosarkom der Chorioidea. Wjestn. O. 1910, S. 62. s34) Waldstein, Zur Kasuistik der Iristumoren. Kl. M. f. A. 68. 1910. ${ }^{535}$ ). Walker, Angiosarkom der Retina. Ophth. Review 1915, S. 176. ${ }^{536}$ ) Wätzold, Tumoren der Caruncula lacrymalis. Berl. Ophth. Ges. 1913. 537) Webster, A case of sarcoma of the orbit. Med. Record 82, 292. 1912. ${ }^{538}$ ) Weekers, Epithélioma térébrant de l'angle interne des paupières. 28. Bulle. tin de la Soc. Belge d'Ophth. 1910. - $\left.{ }^{539}\right)$ Weekers et Mouchet, Tubulöses Sarkom der Aderhaut. Arch. d'O. 1910. - 540) We ks , Endotheliales Augenhöhlensarkom. Verhandlungen der amerik. augenärztl. Ges. 48. Jahreskongre B 1912. 541) Weeks, Zwei metastatische Carcinome der Chorioidea und ein Myxosarkom der Orbita. Ibid. 14, 326. 1915. - ${ }^{542}$ ) Wehrli, Zu den Seefelderschen Urformen des Glioms und zur Gliomgenese. Arch. f. O. G. 79, 166. 1911. - 543) Weidler, Small round cell sarcoma of the orbital cellular tissues. Ophth. Record 20, S. 1 . 1911. - ${ }^{514}$ ) Weidler, Intraocular sarcoma - with report of a case of spontaneous rupture of the globe. Ann. of O. 1915. _- ${ }^{545}$ ) Weisha u pt, Hämorrhagisches Glaukom an einem kataraktösen Auge eines 80 jährigen Mannes, bei dem die anatomische Untersuchung Aderhauttumor ergab. Inaug.-Diss. Heidelberg 1919. - 546) Wells, Melanosarkom der Aderhaut. Ophthalmologie 1914 . 547) Wells und Ma you, Lymphosarkom der Tränendrüse. Transact. of the Ophth. Soc. of the Lnited Kingdom 30, I. 1910. - ${ }^{548}$ ) Wenzel, Über einen malignen Bindehauttumor alveolärer Struktur. Inaug.-Diss. München 1910. — ${ }^{549}$ ) Werbitzky, Melanosarkom des unteren Lides. Moskauer augenärztl. Ges. 1913. 550) Werncke, Ein Fall von Sehnerventumor. Wjestn. O. 1911, S.944. 551) Werncke, Über Ringsarkom des Ciliarkörpers und Flächensarkom der Aderhaut. Russk. Wratsch 13, 436, 1914. - ${ }^{552}$ ) Wescott, Flaches Aderhautsarkom. Verhandlungen der amerik. augenärztl. Ges. 48. Jahreskongre B 1912. $\left.{ }^{5} 53\right)$ Wescott, Case of sarcoma of the ciliary body. Ophth. Record 1912, S. 554. 554) Wessely, Epitheliale Limbuswucherung durch Mesothorium beseitigt. M. M. W. 1914, S. 681. - ${ }^{555}$ ) Wessely, Orbitaltumoren. Ibid. 1917, S. 1621. - ${ }^{556}$ ) Wessely, Ein bisher noch nicht beschriebener Fall von Orbitaltumor. Arch. f. A. 85, 57. 1919. - ${ }^{557}$ ) Wicherkiewicz, Einige Bemerkungen über die Herkunft der sog. Hornhautpapillome. Postęp okulistniczny 1912, S. 69. ${ }^{558}$ ) Wick, Eine seltene Lidgeschwulst (Fibro-Chondro-Epitheliom). Kl. M. f. A. 45, 328. 1920. - ${ }^{559}$ ) Wiener und Alt, On a cace of epithelioma grown on a pterygium. Am. Journ. of O. 1910, S. 361. - ${ }^{560}$ ) Wigodsky, Carcinom der T'ränendrüse. Wjestn. O. 1911, S. 245. - ${ }^{561}$ ) Wigodsky, Gliom der Orbita. Ibid. S. 244. - ${ }^{562}$ ) Wigodsky, Ein Fall von Sarcoma orbitae. Ibid. 1913. 563) Wilder, Rapidly growing round celled sarcoma of orbit. Ophth. Record 1910, S. 326. - ${ }^{564}$ ) Wintersteiner, Das Neuroepithelioma retinae. Leipzig und Wien 1897. Franz Deuticke. - ${ }^{565}$ ) Winters teiner, Infiltrierend fortschreitendes Carcinom in den Lymphspalten der Hornhaut. Wien. Ophth. Ges. 1910. - ${ }^{566}$ ) Wirtz, Vorstellung eines Falles von Krönleinscher Operation wegen eines retrobulbären Epithelioms. Vers. rheinisch-westfälischer Augenärzte 1913. - ${ }^{567}$ ) Wirtz, Weintrauben ̈̈hnliches Papillom der ganzen oberen Übergangs. falte, des Tarsus und der Carunkel. Ibid. 1914. - 568) Wolf r u m, Beginnendes Carcinom der Bindehaut des Augapfels. 37. Vers. O. G. Heidelberg 1911. ${ }^{569}$ ) Wood, Sarkom der Orbita. Ophth. Record 1913. _- ${ }^{570}$ ) Woodward, Five illustrative cases of primary melanosarcoma of the choroid. Ophthalmology 8, 438. 1912. - 5i1) Wray, Leucoma like growth of the iris. Ophth. Review 1911, S. 127. - 572) Wray, Endothelioma of the lacrymal gland. Transact. of the Ophth. Soc. of the United Kingdom 33, 77. 1913._ - 573 ) Za ni, Therapeutische Wirkung des Jequirity in einem Fall von Epitheliom des Limbus cornealis. Ann. 
di Ott. 41. 1912. - 574) Zent ma yer, Intraokulare Geschwulstbildung. College of physicians of Philadelphia 1910. - ${ }^{575}$ ) Ze nt ma yer, Rezidiv eines Chorioidealsarkoms in der Orbita. Americ. Ophth. Soc. 1910. - $\left.{ }^{576}\right)$ Zetsche, Ein Fall von Melanosarkom im phthisischen Auge. Inaug.-Diss. Heidelberg 1910. — ${ }^{577}$ ) Ziegler, A sarcoma of the left orbit. Ophth. Record 1910, S. 214. - 578) Ziegler, Keloid Epithelioma of the lid; Fricke flap. Ibid. 1912, S. 375. - ${ }^{579}$ ) Zirm, Operative Mitteilungen. Z. f. A. 69, Heft 3. 1911. - ${ }^{580}$ ) Zitowsky, Zur Kasuistik der Sehnerventumoren. Wjestn. O. 1913, S. 473.

\section{Nachtrag.}

581) Alt, A case of Lymphangio-Endothelioma of the lower eyelid. Am. Journ. of 0.1910 . - ${ }^{582}$ ) Herbert, A distinctive conjunctival papule. Ophth. Review 1912, S. 125. - 583) Pignatori, Tumori de la superficie corneo-conjuntivale et rapporti colla blefaroschizi. Torino 1913. - 584) Pokrowsky, Ein Fall von Chondrosarkom der Orbita. Russk. Wratsch 1913, S. 1831. - ${ }^{585}$ ) Schneider, Beiträge zur pathologischen Anatomie des Auges: Gliom und Gliose der Netzhaut, Sarkom der Aderhaut, peribulbäres Carcinom. Inaug.-Diss. Marburg 1910. 586) Vermes, Zur Frage der Entstehung des Glioma retinae. Szemészet 1913, Nr. 1. 